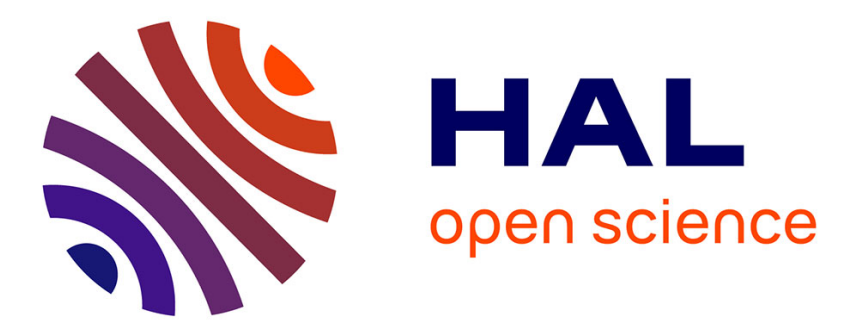

\title{
Present-day formation and seasonal evolution of linear dune gullies on Mars
}

Kelly Pasquon, J. Gargani, M. Massé, Susan J. Conway

\section{To cite this version:}

Kelly Pasquon, J. Gargani, M. Massé, Susan J. Conway. Present-day formation and seasonal evolution of linear dune gullies on Mars. Icarus, 2016, 274, pp.195-210. 10.1016/j.icarus.2016.03.024 . hal01325515

\section{HAL Id: hal-01325515 \\ https://hal.science/hal-01325515}

Submitted on 8 Jan 2021

HAL is a multi-disciplinary open access archive for the deposit and dissemination of scientific research documents, whether they are published or not. The documents may come from teaching and research institutions in France or abroad, or from public or private research centers.
L'archive ouverte pluridisciplinaire HAL, est destinée au dépôt et à la diffusion de documents scientifiques de niveau recherche, publiés ou non, émanant des établissements d'enseignement et de recherche français ou étrangers, des laboratoires publics ou privés. 


\section{Present-day formation and seasonal evolution of linear}

\section{2 dune gullies on Mars}

3 Kelly Pasquon ${ }^{a^{*}}$; Julien Gargania; Marion Masséb; Susan J. Conway ${ }^{b}$

4 a GEOPS, Univ. Paris-Sud, CNRS, University Paris-Saclay, rue du Belvédère, Bat.

5 504-509, 91405 Orsay, France

6 kelly.pasquon@u-psud.fr, julien.gargani@u-psud.fr

7

b LPGN, University of Nantes UMR-CNRS 6112, 2 rue de la Houssinière, 44322 Nantes, France

marion.masse@univ-nantes.fr, susan.conway@univ-nantes.fr

${ }^{*}$ corresponding author 


\section{Abstract}

Linear dune gullies are a sub-type of martian gullies. As their name suggests they only occur on sandy substrates and comprise very long (compared to their width) straight or sinuous channels, with relatively small source areas and almost nonexistent visible deposits. Linear dune gullies have never been observed on terrestrial dunes and their formation process on Mars is unclear. Here, we present the results of the first systematic survey of these features in Mars' southern hemisphere and an indepth study of six dunefields where repeat-imaging allows us to monitor the changes in these gullies over time. This study was undertaken with HiRISE images at 25-30 $\mathrm{cm} /$ pix and $1 \mathrm{~m} /$ pix elevation data derived from HiRISE stereo images. We find the latitudinal distribution and orientation of linear dune gullies is broadly consistent with the general population of martian gullies. They occur predominantly between $36.3^{\circ} \mathrm{S}$ and $54.3^{\circ} \mathrm{S}$, and occasionally between $64.6^{\circ} \mathrm{S}$ and $70.4^{\circ} \mathrm{S}$. They are generally oriented towards SSW (at bearings between $150^{\circ}$ and $260^{\circ}$ ). We find that these gullies are extremely active over the most recent 5 Martian years of images. Activity comprises: (1) appearance of new channels, (2) lengthening of existing channels, (3) complete or partial reactivation, and (4) disappearance of gullies. We find that gully channels lengthen by $\sim 100 \mathrm{~m}$ per year. The intense activity and the progressive disappearance of linear dune gullies argues against the hypothesis that these are remnant morphologies left over from previous periods of high obliquity millions of years ago. The activity of linear dune gullies reoccurs every year between the end of winter and the beginning of spring ( Ls $\left.167.4^{\circ}-216.6^{\circ}\right)$, and coincides with the final stages of the sublimation of annual $\mathrm{CO}_{2}$ ice deposit. This activity often coincides spatially and temporally with the appearance of Recurrent Diffusing Flows (RDFs) digitate-shaped, dark patches with low relative albedo (up to $48 \%$ lower than the adjacent dune) that encompass the active site. South- and SSW-facing dune slopes are those which preferentially host $\mathrm{CO}_{2}$ frost deposits, however, it is only those with angles of $\sim 20^{\circ}$ just below the crest which possess linear dune gullies, suggesting a slope-limited formation process. These observations provide a wealth of temporal and morphometric data that can be used to undertake numerical modelling, to direct future image monitoring and guide laboratory experiments that can be used to better constrain the formation process of these features.

Keywords: Mars; Mars, surface; Mars, climate; Geological processes; Ices. 


\section{Introduction}

\subsection{Martian gullies and linear dune gullies}

Martian gullies were first reported by Malin and Edgett (2000) and are kilometer-scale features generally composed of an alcove, a channel and a debris apron. Gullies are most commonly observed on crater walls (e.g., Malin and Edgett, 2000; Harrison et al., 2015), but are also found on the faces of dunes (e.g., Diniega et al., 2010; Hansen et al., 2011; Dundas et al., 2012). Some gullies are active today (e.g., Diniega et al., 2010; 2013; Hansen et al., 2011; Dundas et al., 2010; 2012; 2015; Raack et al., 2015). In addition to "classic" gullies with an alcove-channelapron morphology dunes and sandy slopes also host so-called "linear" dune gullies (e.g., Mangold et al., 2003; Reiss and Jaumann, 2003; Reiss et al., 2010; Dundas et al., 2012; Jouannic, 2012; Jouannic et al., 2012; Diniega et al., 2013). Linear dune gullies are characterized by series of sub-parallel channels with relatively restricted source areas; they are of almost constant width along their length and are thought to have a perched channel in the lower part of the channel (Jouannic et al. 2015). These gullies often end in a circular depression called a "pit" (e.g. Mangold et al., 2003; Reiss and Jaumann, 2003; Reiss et al., 2010; Jouannic et al., 2012). The origin of these linear dune gullies is enigmatic, partly because they have never been observed on terrestrial dunes.

\subsection{Background on linear dune gullies}

Linear dune gullies occur on intra-crater dunefields. Dunefields are low in albedo and are relatively common on Mars (Thomas, 1982). Their total surface area

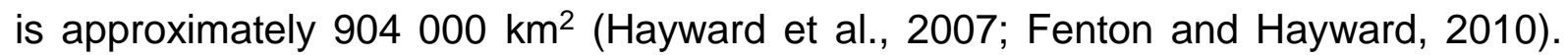
Spectroscopic studies suggest that these dunes are mainly composed of volcanic sands with basaltic (Paige and Keegan, 1994; Herkenhoff and Vasavada, 1999) or andesitic (Bandfield, 2002) origin. On Mars, dunefields are most common at latitudes above $40^{\circ} \mathrm{S}$ and around the North polar cap $\left(>75^{\circ} \mathrm{N}\right)$ (Hayward et al., 2014).

In previous studies linear dune gullies have been reported on ten different intra-crater dunefields: Russell (54.3 $\left.3^{\circ} \mathrm{S}, 13^{\circ} \mathrm{E}\right)$ (e.g., Mangold et al., 2003; Reiss and Jaumann, 2003; Reiss et al., 2010; Dundas et al., 2012; Jouannic, 2012; Jouannic et al., 2012), Green (52.7 $\left.{ }^{\circ} \mathrm{S}, 351.5^{\circ} \mathrm{E}\right)$ (Reiss and Jaumann, 2003), Kaiser (47.2 ${ }^{\circ} \mathrm{S}$, $19.5^{\circ} \mathrm{E}$ ) (Mangold et al., 2003; Dundas et al., 2012; Diniega et al., 2013), Matara 
$\left(49.5^{\circ} \mathrm{S}, 34.7^{\circ} \mathrm{E}\right)$ (Dundas et al., 2012; Diniega et al., 2013), Proctor (47.1 $\left.{ }^{\circ} \mathrm{S}, 30.7^{\circ} \mathrm{E}\right)$, Rabe $\left(43.6^{\circ} \mathrm{S}, 34.8^{\circ} \mathrm{E}\right)$ (Reiss et al., 2007) and four unnamed craters $\left(47.2^{\circ} \mathrm{S}, 34^{\circ} \mathrm{E}\right.$; $49^{\circ} \mathrm{S}, 27.2^{\circ} \mathrm{E} ; 50.3^{\circ} \mathrm{S}, 292.1^{\circ} \mathrm{E}$ and $49.7^{\circ} \mathrm{S}, 293.7^{\circ} \mathrm{E}$ ) (Mangold et al., 2003; Reiss and Jaumann, 2003; Reiss et al., 2007; Dundas et al., 2012). Unlike the surveys of classic gullies, which have been widespread and global (Diniega et al., 2010; Harrison et al., 2015), no systematic survey of linear dune gullies has been reported in the literature.

When linear dune gullies were first reported in the literature, it was proposed that they formed several million years ago during periods of high orbital obliquity (Costard et al., 2002; Mangold et al., 2003). Recent observations from repeat-images suggest that linear dune gullies are still active; this activity includes the formation of new channels and new pits (Reiss and Jaumann, 2003; Reiss et al., 2010; Dundas et al., 2012; Diniega et al., 2013). However, it is still unknown whether linear dune gullies are a relic from previous periods of high obliquity that are now undergoing modification, or whether their origin, in and of itself, is recent.

Multiple processes have been put forward to explain the formation of linear dune gullies including: (i) water-supported debris flow (Costard et al., 2002; Mangold et al., 2003; Reiss and Jaumann, 2003; Miyamoto et al., 2004; Védie et al., 2008; Reiss et al., 2010; Jouannic et al., 2012; 2015), (ii) defrosting processes, glacial-like creep and rolling sand-ice $\left(\mathrm{CO}_{2}\right.$ and/or $\left.\mathrm{H}_{2} \mathrm{O}\right)$ aggregates (Di Achille et al., 2008), (iii) sliding $\mathrm{CO}_{2}$ blocks (Dundas et al., 2012; Diniega et al., 2013), (iv) sand fluidization by $\mathrm{CO}_{2}$ sublimation (Pilorget and Forget, 2015). None of these hypotheses have been able to explain all the morphological features of linear dune gullies.

\subsection{Frost and activity on Martian dunes}

In autumn and winter, as the temperature falls $\mathrm{CO}_{2}$ frost is deposited on the surface of Mars and increases the albedo of the surface. This deposit is continuous above $\sim 60^{\circ}$ latitude, is discontinuous from $30^{\circ}$ to $60^{\circ}$ of latitude (Schorghofer and Edgett, 2006; Vincendon et al., 2010b; Diniega et al., 2013), and can only be found on pole facing slopes nearer the equator (Dundas et al., 2015). Most of this ice deposit is composed of $\mathrm{CO}_{2}$ (Diniega et al., 2013; Dundas et al., 2015), and $\mathrm{H}_{2} \mathrm{O}$ is a minor component (Kereszturi et al., 2009; Gardin et al., 2010; Vincendon et al., 2010b). The thickness of this deposit can be up to meters (Smith et al., 2001), but at lower latitudes it is acknowledged to be sub-centimeter (Vincendon, 2015). 
On dunes, a lot of different active seasonal processes have been observed, including: activity of gullies (Diniega et al., 2010), dark spots (Kereszturi et al., 2009; 2011), dark flows (Möhlmann and Kereszturi, 2010; Kereszturi et al., 2011; Kieffer et al., 2006) dark fans (Kieffer et al., 2000), and dust devil tracks (Verba et al., 2010). All of these features, with the exception of dust devils, have been attributed to the defrosting of the seasonal $\mathrm{CO}_{2}$ ice deposit. Previous studies have linked the activity of linear dune gullies to this suite of seasonal defrosting processes (Reiss and Jaumann, 2003; Reiss et al., 2010; Dundas et al., 2012; Diniega et al., 2013), but only a few selected dunefields have been studied in detail.

\subsection{Objectives of this study}

The main objectives of this study are thus to:

- Undertake a systematic survey of linear dune gullies in all available High Resolution Imaging Science Experiment (HiRISE) images of dunefields in the southern hemisphere in order to identify their latitudinal distribution (as has been done for classic gullies).

- Where repeat-images are available, undertake detailed studies of the activity of linear dune gullies, with the aim to constrain the relative timing of different activities and any associated frosts/morphologies across multiple dunefields.

- Compare and contrast the main hypotheses associated with the formation of linear dune gullies in light of our findings.

For brevity, in the rest of this paper, "linear dune gullies" will be simply called "linear gullies".

\section{Methods}

\section{1. Survey and morphology}

This study of linear gullies is based on the analysis of HiRISE images and HiRISE Digital Terrain Models (DTM). The HiRISE camera, onboard MRO (Mars Reconnaissance Orbiter) spacecraft, possesses 14 CCD (Charge-Coupled Device) detectors, which operate in the visible (from 536 to $692 \mathrm{~nm}$ ) and in the infrared (approximately $874 \mathrm{~nm}$ ) (McEwen et al., 2010). In order to identify the presence, or absence of linear gullies, we inspected all HiRISE images which covered dunefields 
identified by Hayward et al. (2014), and included additional images in which we noted the presence of dark sand dunes (excluding crater walls) using the HiRISE footprint layer in Google Mars.

For dunefields with linear gullies and where sufficient repeat HiRISE images were available, we undertook a more detailed analysis of the changes between images, or "activity". The timing of activity in this paper is described using the Solar Longitude (Ls) of the first image where we observe a morphologic change and the Ls when no more changes are overserved. For these dunefields we divided the image into "sites", where a site is defined as a section of a dune face which hosts a continuous suite of linear gullies. Therefore, each site contains a different number of linear gullies and has a range of surface areas (which typically does not exceed $0.7 \mathrm{~km}^{2}$ ). For each site the typical orientation of the gullies was measured by drawing a straight line from the source of a randomly selected gully to its channel terminus and taking the bearing from north of this line. Changes between images were identified on the RDR (Reduced Data Record) georeferenced images. The length and width of gully channels were directly measured on the RDR images.

HiRISE Digital Terrain Models (DTM) (hirise.Ipl.arizona.edu) are available for two of the studied dunefields (those in Kaiser and Proctor Crater). These DTMs have a vertical precision in the tens of centimeters (hirise.lpl.arizona.edu) and were produced from two pairs of stereographic images (PSP_003800_1325 and PSP_004077_1325 for Proctor and ESP_013017_1325 and ESP_013083_1325 for Kaiser). Slope angles were measured for each site with active linear gullies, and also for surrounding sites without linear gully activity. For each site, slope angles were measured by taking a topographic profile along the line of steepest decent on the dune and undertaking a linear fit over the area of interest. We took slope angle measurements just below the crest of the dune (the first $20 \%$ of the downslope length of the profile) and for the whole dune profile.

\section{2. Spectral properties and albedo}

We first investigated whether we could use CRISM (Compact Reconnaissance Imaging Spectrometer for Mars) data to identify the surface composition where we observe seasonal changes (e.g., Recurrent Diffusing Flows). CRISM is an imaging spectrometer with a resolution of $18 \mathrm{~m} /$ pixel which covers wavelengths from 383 to $3960 \mathrm{~nm}$ (visible to infrared) (Murchie et al., 2004). Data were atmospherically 
corrected, parameterized and map-projected using the standard IDL/ENVI procedures provided in the CRISM analysis toolkit (http://pdsgeosciences.wustl.edu/missions $/ \mathrm{mro} / \mathrm{crism}$.htm). We undertook a systematic search for hydration bands $(1.9,1.5,3.0 \mu \mathrm{m})$, and/or $\mathrm{CO}_{2}$ bands $(1.4,2.3,4.6 \mu \mathrm{m})$ in the resulting spectra. The resolution of CRISM data $(18 \mathrm{~m} / \mathrm{pixel})$ is theoretically appropriate for the size of the studied features (1-50 $\mathrm{m}$ in width, and sometimes $200 \mathrm{~m}$ in width when features are close together). However, CRISM data are temporally sparse (few repeats) and in our areas of interest we were unable to obtain any useful data for the following reasons: 1) some of the features of interest were too small to be resolved by CRISM and the extent of the CRISM images did not cover the larger features which could have been resolved (CRISM 00005C69 Ls: 240.9'; CRISM 0001C413 Ls: $192.3^{\circ}$ ) and 2) one of the available CRISM cubes was obscured by clouds (CRISM 00004512 Ls: $185.9^{\circ}$ ).

We therefore did not pursue CRISM data analysis, but instead undertook measurements of relative albedo from HiRISE images, a method which has been used in previous work to provide information about water and ices (McEwen et al., 2011; Massé et al., 2014). We measured the relative HiRISE albedo of features that occur in association with linear gullies. We sampled uniform areas with no significant variations in topography to exclude the influence of shadowing on albedo differences. With IDL/ENVI, the mean data number (DN) values were calculated on reference zones in the RED (570-830 nm) HiRISE RDR products. Reference regions were selected on dune surfaces with a similar orientation and slope to, but away from, the feature of interest. This reference zone was generally $50 \mathrm{~m} \times 10 \mathrm{~m}$ in size. Relative albedo was then calculated between the feature of interest and the reference zone. We did not study the change of albedo with time for any given feature of interest. Atmospheric effects were accounted for by subtracting the minimum DN in the image (DNatmosphere), which is normally located in a deep shadow. $D N_{\text {atmosphere }}$ had a value of 3 in all cases due to the stretch applied to all HiRISE RDRs (Daubar et al., 2015). The PDS label provides the required information for converting the DN value to I/F (units of reflectance, i.e. Intensity/Flux) as follows: $\mathrm{I} / \mathrm{F}$ value = DN * SCALING_FACTOR + OFFSET (McEwen and Eliason, 2007). Finally relative albedo was calculated with the equation (Daubar et al., 2015):

$$
A_{\text {relative }}=\frac{A_{\text {sample }}}{A_{\text {reference }}}=\frac{\left(D N_{\text {sample }}-D N_{\text {atmosphere }}\right)}{\left(D N_{\text {reference }}-D N_{\text {atmosphere }}\right)}
$$


where $A$ refers to albedo and $A_{\text {relative }}$ is the relative albedo, subscript sample refers to the area of interest, and subscript reference refers to the reference surface.

\section{Results}

\subsection{Distribution}

From a total of 393 HiRISE images identified as containing dunefields, or sand-rich areas in the southern hemisphere of Mars (Supplementary Table 1), we find 33 locations with dunes, or dunefields containing linear gullies (Table 1; Fig. 1).

Linear gullies are concentrated in a latitudinal band ranging from $36.3^{\circ} \mathrm{S}$ to $54.3^{\circ} \mathrm{S}$, and also occur between $64.6^{\circ} \mathrm{S}$ to $70.4^{\circ} \mathrm{S}$ (Fig. 1). From this initial dataset, we focused our study on six intra-crater dunefields with repeat-images, including: Rabe, Kaiser, Unnamed $\left(47.2^{\circ} \mathrm{S}, 34^{\circ} \mathrm{E}\right)$, Proctor, Matara, and Hellespontus Montes (Table 1; Fig. 1B). For these 6 dunefields, 357 individual "sites" containing gullies were defined and each of these sites was imaged multiple times, totaling 116 images. All in all 5190 individual observations were conducted.

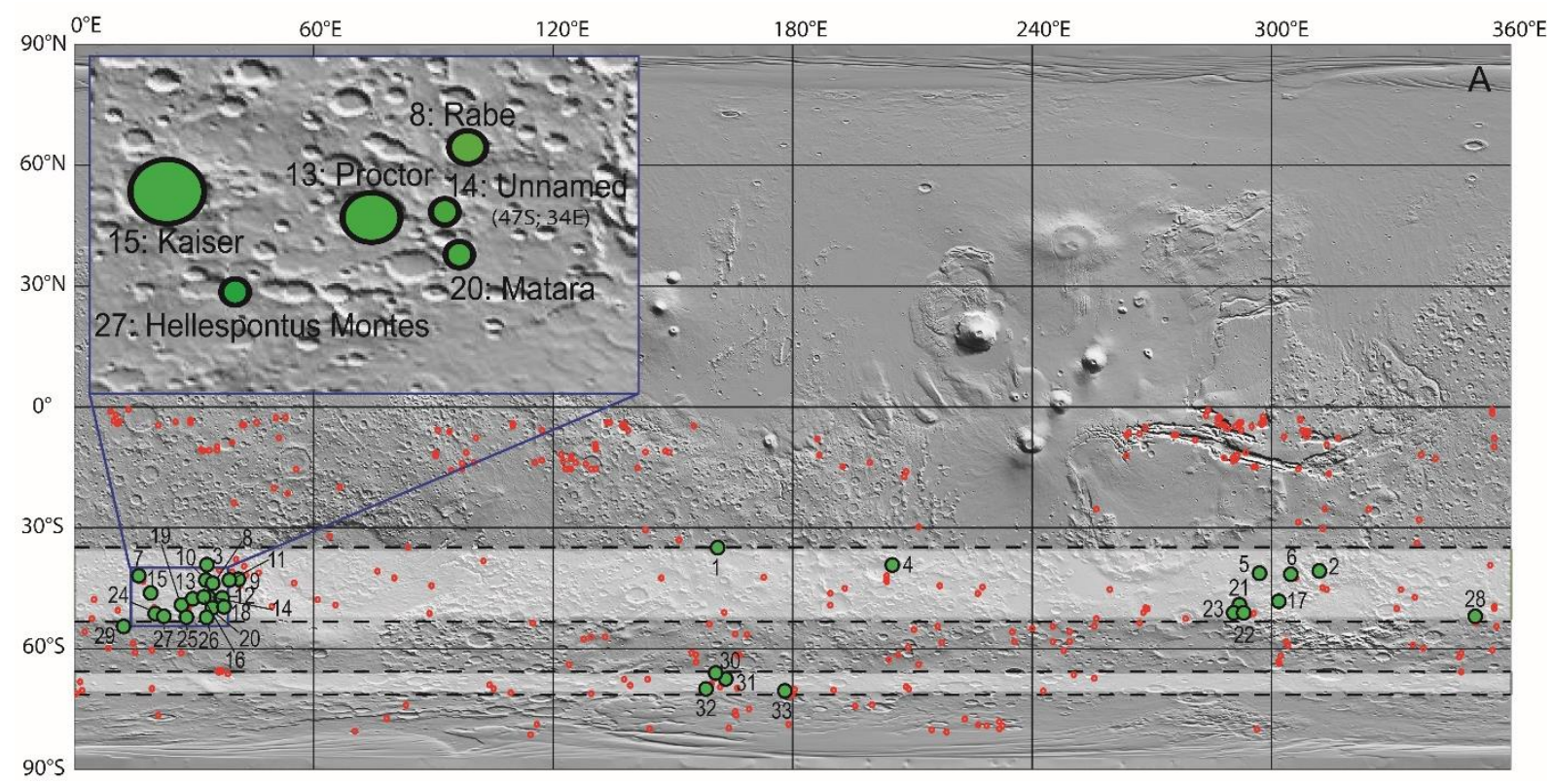

Fig. 1. A) The location of HiRISE images with (green points) and without (red outlines) linear gullies on dunefields, or sand-rich areas in the southern hemisphere overlain on a global shaded relief map. In total 353 images were included in the survey (Table 1; Supplementary Table 1). Lighter-shaded areas highlight the latitude bands in which linear dune gullies occur. Numbers refer to the location numbers given in Table 1. B) Detailed view of the six intra-crater dunefields, where linear gullies are studied in more detail in this paper. The points are labelled with location numbers in Table 1, followed by the name of the crater. 


\begin{tabular}{|c|c|c|c|c|c|}
\hline $\begin{array}{l}\text { Location } \\
\text { Number }\end{array}$ & Name & Latitude & Longitude & $\begin{array}{c}\text { Number of } \\
\text { HiRISE } \\
\text { images of } \\
\text { dunes }\end{array}$ & $\begin{array}{c}\text { Number of } \\
\text { overlapping } \\
\text { HiRISE } \\
\text { images of } \\
\text { dunes (max) }\end{array}$ \\
\hline 1 & $\begin{array}{l}\text { Terra Cimmeria } \\
\text { Unnamed crater }\end{array}$ & $36.3^{\circ} \mathrm{S}$ & $158.2^{\circ} \mathrm{E}$ & 3 & 3 \\
\hline 2 & Unnamed crater & $40.5^{\circ} \mathrm{S}$ & $309.9^{\circ} \mathrm{E}$ & 4 & 4 \\
\hline 3 & Unnamed crater & $40.8^{\circ} \mathrm{S}$ & $34.4^{\circ} \mathrm{E}$ & 2 & 1 \\
\hline 4 & Unnamed crater & $41.1^{\circ} \mathrm{S}$ & $203.5 \mathrm{E}^{\circ}$ & 4 & 4 \\
\hline 5 & Unnamed crater & $41.2^{\circ} \mathrm{S}$ & $297.6^{\circ} \mathrm{E}$ & 2 & 1 \\
\hline 6 & Unnamed crater & $41.2^{\circ} \mathrm{S}$ & $306.9^{\circ} \mathrm{E}$ & 1 & 1 \\
\hline 7 & Unnamed crater & $43.3^{\circ} \mathrm{S}$ & $17.7^{\circ} \mathrm{E}$ & 2 & 2 \\
\hline${ }^{*} 8$ & Rabe crater & $43.6^{\circ} \mathrm{S}$ & $34.8^{\circ} \mathrm{E}$ & 8 & 3 \\
\hline 9 & Unnamed crater & $45.4^{\circ} \mathrm{S}$ & $38.8^{\circ} \mathrm{E}$ & 1 & 1 \\
\hline 10 & Unnamed crater & $45.5^{\circ} \mathrm{S}$ & $34^{\circ} \mathrm{E}$ & 6 & 6 \\
\hline 11 & Unnamed crater & $45.6^{\circ} \mathrm{S}$ & $36.8^{\circ} \mathrm{E}$ & 15 & 11 \\
\hline 12 & Unnamed crater & $47.1^{\circ} \mathrm{S}$ & $37.3^{\circ} \mathrm{E}$ & 4 & 2 \\
\hline${ }^{*} 13$ & Proctor crater & $47.1^{\circ} \mathrm{S}$ & $30.7^{\circ} \mathrm{E}$ & 23 & 9 \\
\hline *14 & Unnamed crater & $47.2^{\circ} \mathrm{S}$ & $34^{\circ} \mathrm{E}$ & 9 & 5 \\
\hline${ }^{*} 15$ & Kaiser crater & $47.2^{\circ} \mathrm{S}$ & $19.5^{\circ} \mathrm{E}$ & 25 & 21 \\
\hline 16 & Unnamed crater & $47.2^{\circ} \mathrm{S}$ & $34^{\circ} \mathrm{E}$ & 12 & 8 \\
\hline 17 & Unnamed crater & $48^{\circ} \mathrm{S}$ & $301.1^{\circ} \mathrm{E}$ & 3 & 3 \\
\hline 18 & Unnamed crater & $48.6^{\circ} \mathrm{S}$ & $37.6^{\circ} \mathrm{E}$ & 1 & 1 \\
\hline *19 & Unnamed crater & $\begin{array}{c}\text { Iconn } 49^{\circ} \\
\mathrm{S}\end{array}$ & $27.2^{\circ} \mathrm{E}$ & 19 & 19 \\
\hline${ }^{*} 20$ & Matara crater & $49.5^{\circ} \mathrm{S}$ & $34.7^{\circ} \mathrm{E}$ & 46 & 42 \\
\hline *21 & Aonia Terra dunes & $49.7^{\circ} \mathrm{S}$ & $293.7^{\circ} \mathrm{E}$ & 10 & 9 \\
\hline 22 & Unnamed crater & $50^{\circ} \mathrm{S}$ & $294.6^{\circ} \mathrm{E}$ & 11 & 11 \\
\hline *23 & Unnamed crater & $50.3^{\circ} \mathrm{S}$ & $292.1^{\circ} \mathrm{E}$ & 6 & 6 \\
\hline 24 & Unnamed crater & $52^{\circ} \mathrm{S}$ & $18.2^{\circ} \mathrm{E}$ & 6 & 6 \\
\hline 25 & Unnamed crater & $52^{\circ} \mathrm{S}$ & $28.5^{\circ} \mathrm{E}$ & 4 & 4 \\
\hline 26 & Unnamed crater & $52.1^{\circ} \mathrm{S}$ & $33.4^{\circ} \mathrm{E}$ & 2 & 2 \\
\hline 27 & $\begin{array}{l}\text { Hellespontus Montes } \\
\text { crater }\end{array}$ & $52.2^{\circ} \mathrm{S}$ & $23^{\circ} \mathrm{E}$ & 5 & 5 \\
\hline${ }^{*} 28$ & Green crater & $52.7^{\circ} \mathrm{S}$ & $351.5^{\circ} \mathrm{E}$ & 4 & 4 \\
\hline *29 & Russell crater & $54.3^{\circ} \mathrm{S}$ & $13^{\circ} \mathrm{E}$ & 74 & 74 \\
\hline 30 & Unnamed crater & $64.6^{\circ} \mathrm{S}$ & $158.3^{\circ} \mathrm{E}$ & 9 & 9 \\
\hline 31 & $\begin{array}{l}\text { Terra Cimmeria } \\
\text { Unnamed crater }\end{array}$ & $66.1^{\circ} \mathrm{S}$ & $161.6^{\circ} \mathrm{E}$ & 10 & 8 \\
\hline 32 & Jeans crater & $69.5^{\circ} \mathrm{S}$ & $153.4^{\circ} \mathrm{E}$ & 30 & 27 \\
\hline 33 & Unnamed crater & $70.4^{\circ} \mathrm{S}$ & $178.2^{\circ} \mathrm{E}$ & 30 & 30 \\
\hline
\end{tabular}

231 Table 1. Location of dunefields with linear gullies, with the six locations where a more detailed study is

232 undertaken highlighted in grey. ${ }^{*}$ Dunefields where linear gullies have been reported in previous

233 studies (Mangold et al., 2003; Reiss and Jaumann, 2003; Reiss et al., 2007; 2010; Dundas et al., 234 2012; Jouannic, 2012; Jouannic et al., 2012; Diniega et al., 2013).

\subsection{Linear gully morphology}

Here we present a description of the common morphological attributes of 237 linear gullies, which results from our detailed observations in Rabe, Kaiser, Unnamed $238\left(47.2^{\circ} \mathrm{S}, 34^{\circ} \mathrm{E}\right)$, Proctor, Matara, and Hellespontus Montes dunefields. We find that 239 linear gullies in these locations always have a channel, and these channels range 
240 from highly sinuous to almost straight (Figs. 2A-C). Levees are often present along 241 the channel and channels form tributary systems (Figs. 2A,B,D,F). We observe that, 242 although many linear gullies start at the crest of the dune, they can start at any 243 location on the dune profile. They do not always possess a readily observed, well244 defined alcove. These gullies terminate in: i) a pit (Figs. 2A,B), ii) a linear succession 245 of pits (Figs. 2B,C,D,F), iii) a group of non-aligned pits (Fig. 2C), or iv) a smooth fan 246 surface (3 to 4 times wider than the channel) surrounded in its lowest part by 247 numerous non-aligned pits. Sometimes channels are present in this smooth-fan area 248 (Figs. 2E,G). Sometimes pits can be observed without associated channels, for which 249 we use the term "unconnected pits" for brevity in this paper (Figs. 2H,I).

250 In Matara crater we measured the lengths and widths of the linear gully 251 channels. Their lengths range from a few meters to several hundred meters with a 252 mean of $120 \mathrm{~m}$ (Fig. 4A) and their widths range from 1 to $10 \mathrm{~m}$. Pits can be up to $25310 \mathrm{~m}$ in diameter. 


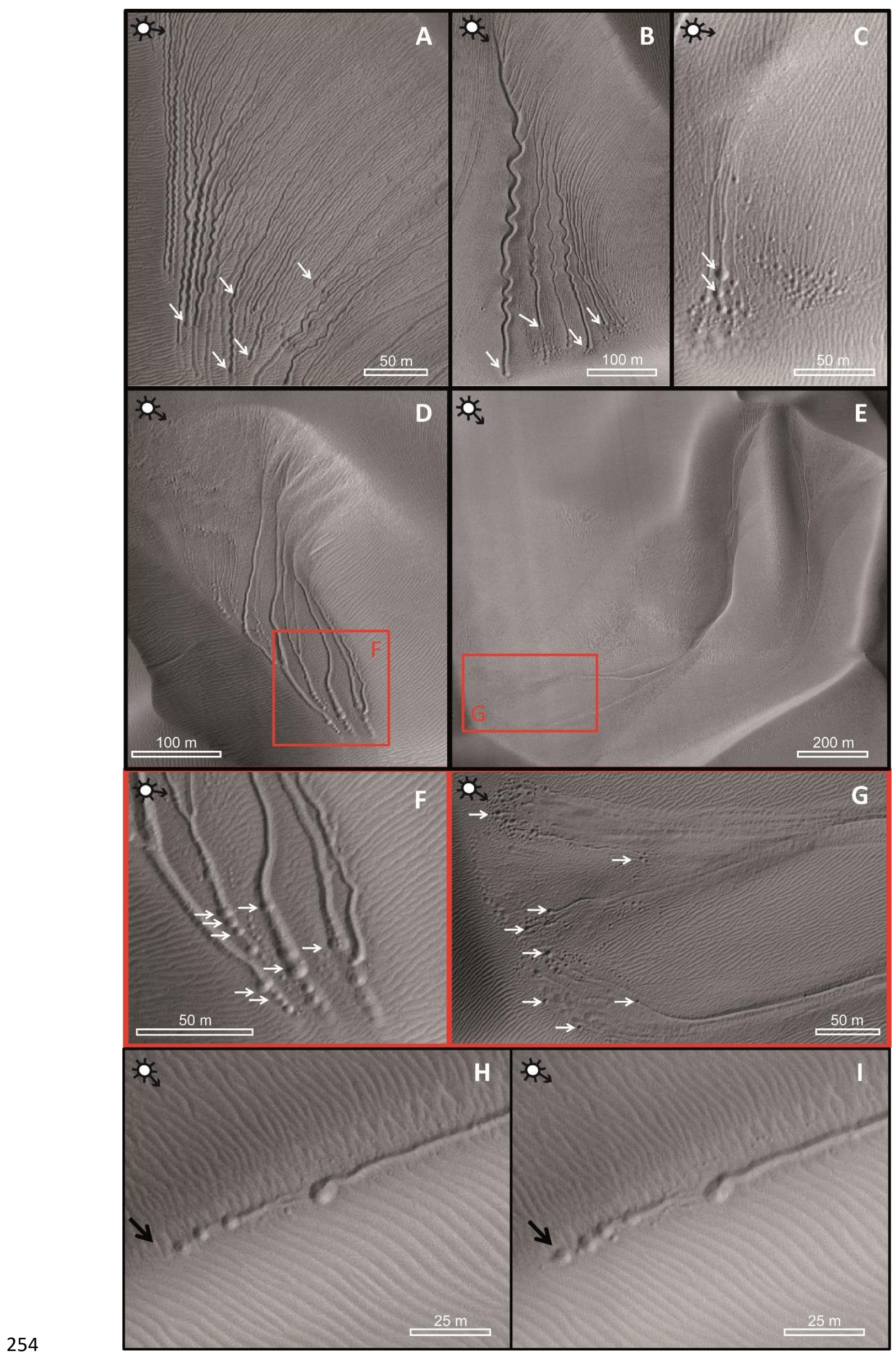


Fig. 2. Linear gullies on Kaiser and Matara crater dunefields. White arrows show the location of pits. A) Highly sinuous linear gullies (Kaiser crater MY29 Ls: 198.7, HiRISE Image: ESP_011738_1325). B) Sinuous linear gullies. (Matara crater, MY31 Ls: $254.8^{\circ}$, HiRISE image: ESP_030528_1300). C) Lowsinuosity linear gullies and non-aligned pit groups (Matara crater, MY32 Ls: 201.9', HiRISE image: ESP_038255_1300). D) Linear gullies with an alcove, a single channel, and terminating in a pit or a succession of pits (Matara crater, MY30 Ls: 208.8 , HiRISE image: ESP_020770_1300). E) Linear gullies with an alcove, a single channel, and terminating with a smooth fan, surrounded in its lower part by numerous non-aligned pits. Channels are present on the smooth fan. (Matara crater dunefield MY30 Ls: 208.8 ${ }^{\circ}$, HiRISE image: ESP_020770_1300). F) Detailed view of terminal part of linear gullies in D. G) Detailed view of terminal part of linear gullies in E. H and I) Pits observed on the same area at two different times showing the appearance of a new unconnected pit (Matara crater, MY30,

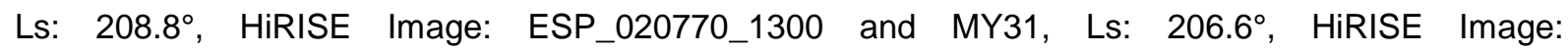
ESP_029539_1305). Black arrows indicate the same position in the two images for reference.

\subsection{Changes in linear gully morphology}

We observe four different types of changes in linear gullies: (1) appearance of new linear gullies, (2) lengthening of existing channels, (3) reactivation (complete or partial) and (4) fading. The channels of linear gullies in Matara crater lengthen by 1 to 550 meters in one Martian year (Fig. 4B). A complete reactivation is where a new linear gully follows exactly the same track as that taken by a previous gully. A partial reactivation means that a new linear gully follows a pre-existing track, but not over its entire length. It either: (i) stops before the old terminal pit or, (ii) changes direction in the lower part and creates a new gully-channel. "Fading" is where we observe the gradual disappearance of linear gullies and their infilling and/or replacement by ripples. In extreme cases linear gullies can fade almost completely in the year following their appearance, or more usually in 2 or 3 years after they appeared (Fig. 3). Groups of pits associated with very short channels (only meters in length) also often fade in the space of one year (Fig. 3).
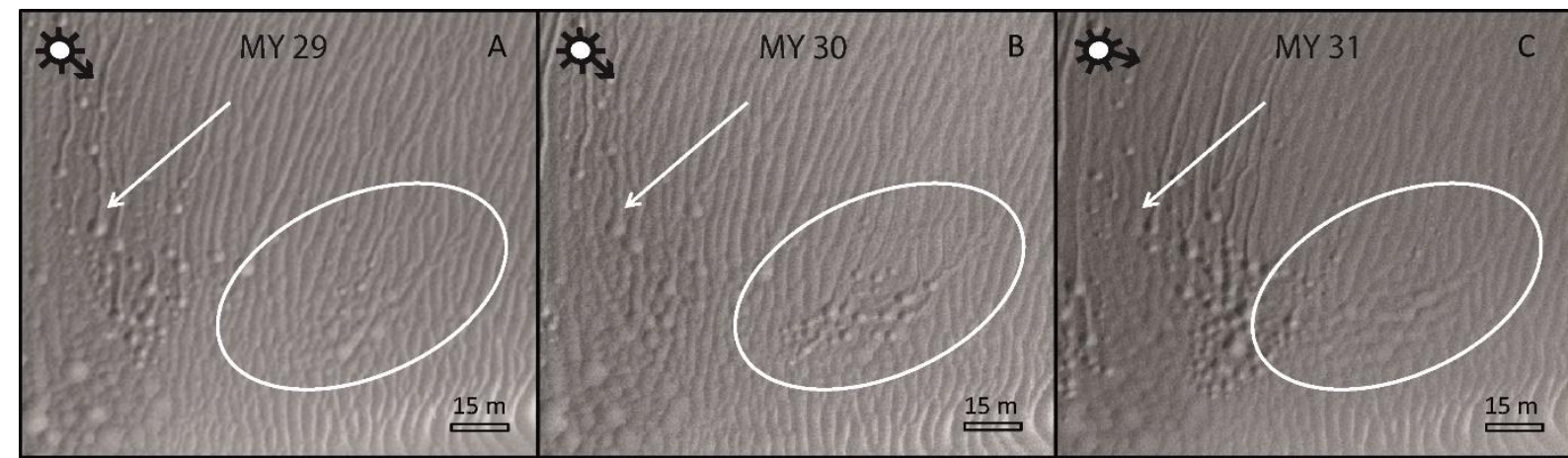
Fig. 3. Fading of linear gullies on Matara dunefields. White circles show: A) the initial dune surface without linear gullies (MY29 Ls: 300.2 $2^{\circ}$, HiRISE Image: ESP_013834_1300), B) the appearance of small linear gullies and a group of pits (MY30 Ls: 208.8 ${ }^{\circ}$, HiRISE Image: ESP_020770_1300), C) the partial infilling, or fading of these linear gullies and pits (MY31 Ls: 199.8 ${ }^{\circ}$, HiRISE Image: ESP_029394_1300). White arrows indicate the position of a linear gully in A, which gradually fades over two Martian years (in B and C).

We divided the activity of linear gullies into three different categories: (i) 290 "strong" activity was where there was the appearance or lengthening of at least 3 291 linear gullies in the same site over one Martian year, (ii) "low" activity, was where 292 there was activity, but it did not fulfil the criteria for "strong", and (iii) finally "no 293 activity" was assigned to sites where there were no new linear gullies and no 294 lengthening for all Martian years studied.

Out of the 357 sites with linear gullies that we studied, 83 (23\%) of them have 296 strong activity, 107 (30\%) of them have low activity and 158 of them have no activity. 297 Therefore more than $50 \%$ of the sites that we studied were active (Table 2 ). 

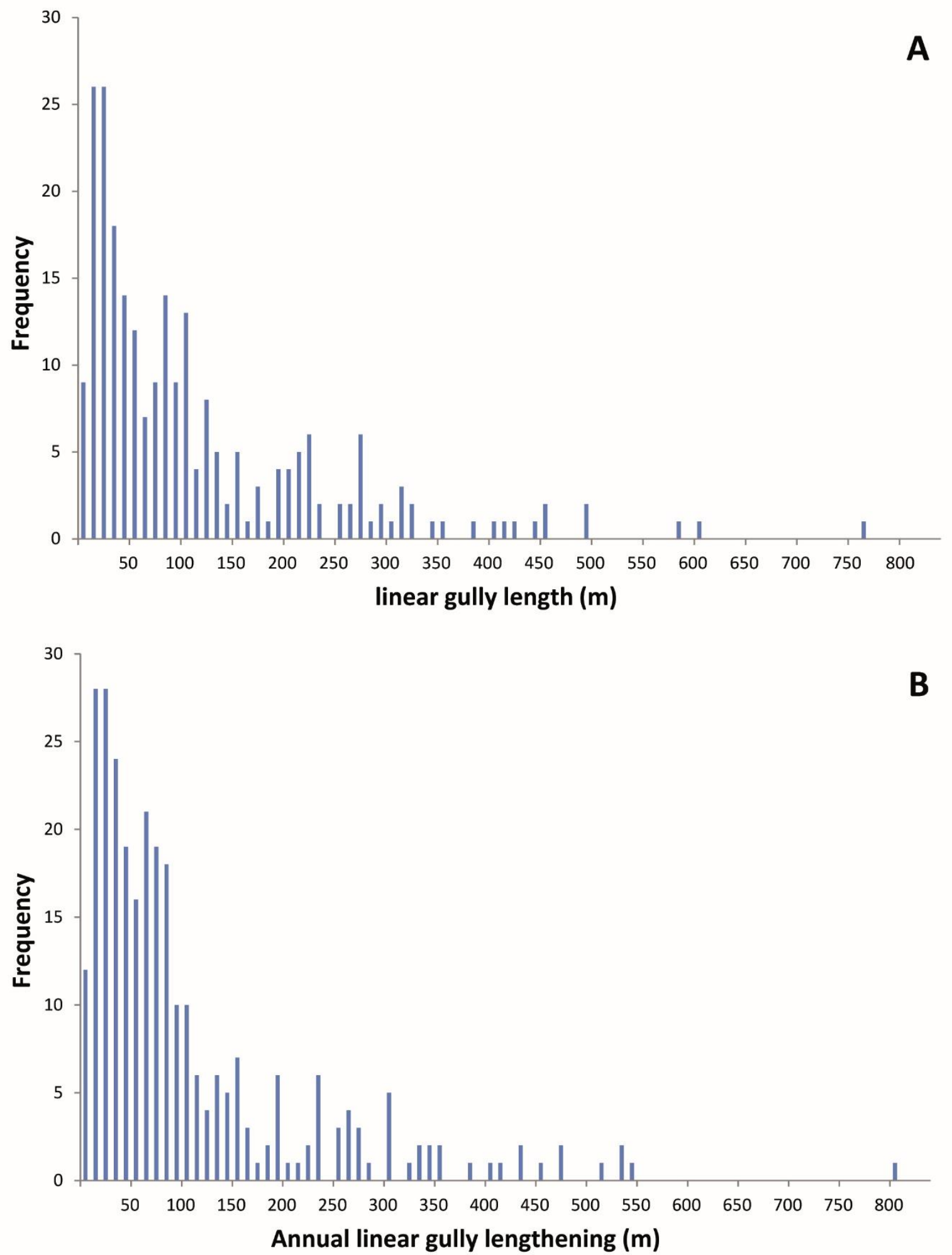

299 Fig. 4. A) A histogram of linear gully length in meters for Matara crater dunefield $(+/-2 \mathrm{~m})$, 300 measurements are reported in $10 \mathrm{~m}$ bins, the total number of measurements is 291 , and the y-axis 301 label "frequency" signifies the number of measurements included per bin. B) A histogram of the 302 lengthening of linear gully channels per Martian year for Matara crater dunefields. The lengthening 303 was measured between two images which were approximately one year apart $(+/-2 \mathrm{~m})$. 

label "frequency" signifies the number of measurements included per bin.

\begin{tabular}{|c|c|c|c|c|c|}
\hline $\begin{array}{l}\text { Dunefield } \\
\text { name }\end{array}$ & $\begin{array}{l}\text { Nr. sites with } \\
\text { linear gullies }\end{array}$ & $\begin{array}{l}\text { Nr. sites with } \\
\text { active linear } \\
\text { gullies }\end{array}$ & $\begin{array}{l}\text { Nr. sites with } \\
\text { strong } \\
\text { activity }\end{array}$ & $\begin{array}{l}\text { Nr. sites with } \\
\text { RDFs }\end{array}$ & $\begin{array}{c}\text { Max. number } \\
\text { of images per } \\
\text { year }\end{array}$ \\
\hline Rabe & 26 & 12 & 3 & 0 & 2 \\
\hline Kaiser & 43 & 20 & 3 & 28 & 9 \\
\hline $\begin{array}{c}\text { Unnamed } \\
\left(47.2^{\circ} S ; 34^{\circ} \mathrm{S}\right)\end{array}$ & 66 & 18 & 1 & 2 & 2 \\
\hline Proctor & 80 & 30 & 18 & 9 & 3 \\
\hline Matara & 125 & 94 & 50 & 24 & 13 \\
\hline Hellesp.M. & 17 & 15 & 7 & 12 & 2 \\
\hline Total & 357 & 189 & 82 & 75 & - \\
\hline
\end{tabular}

Table 2. Summary data for the sites surveyed in the 6 dunefields studied. For Martian years 28, 29, 30, and 31. Abbreviations: "Hellesp.M." stands for Hellespontus Montes, "Nr." for number, "Max." for Maximum and "RDF", "Recurrent Diffusing Flow".

At the locations of some of the new linear gullies, we observe the development of a low albedo patch, which we term a "Recurrent Diffusing Flow" (RDF; Figs. 5C; 6; 10B,C). Some of these RDFs are aligned along the linear gully channels and seem to remain confined within them (Fig. 6A). Other RDFs are not confined to the gullychannel (Figs. 5C; 6B,C; 10B,C) and can be 10 times wider than the gully. The RDFs seem to originate from a single point and they get between 2 to 25 times wider from top to bottom. Generally, RDFs originate at the crest of their host dune. The length of RDFs and linear gullies is generally similar. A RDF never extends further than a few meters past the end of a linear gully (Figs. 6B; 10B,C). RDF margins sometimes have a higher albedo, "white halo". This white halo can be present around the whole perimeter of a RDF (Fig. 6C), or only along some parts of it (Fig. 5C). RDFs are observed in 75 sites (Table 2). 


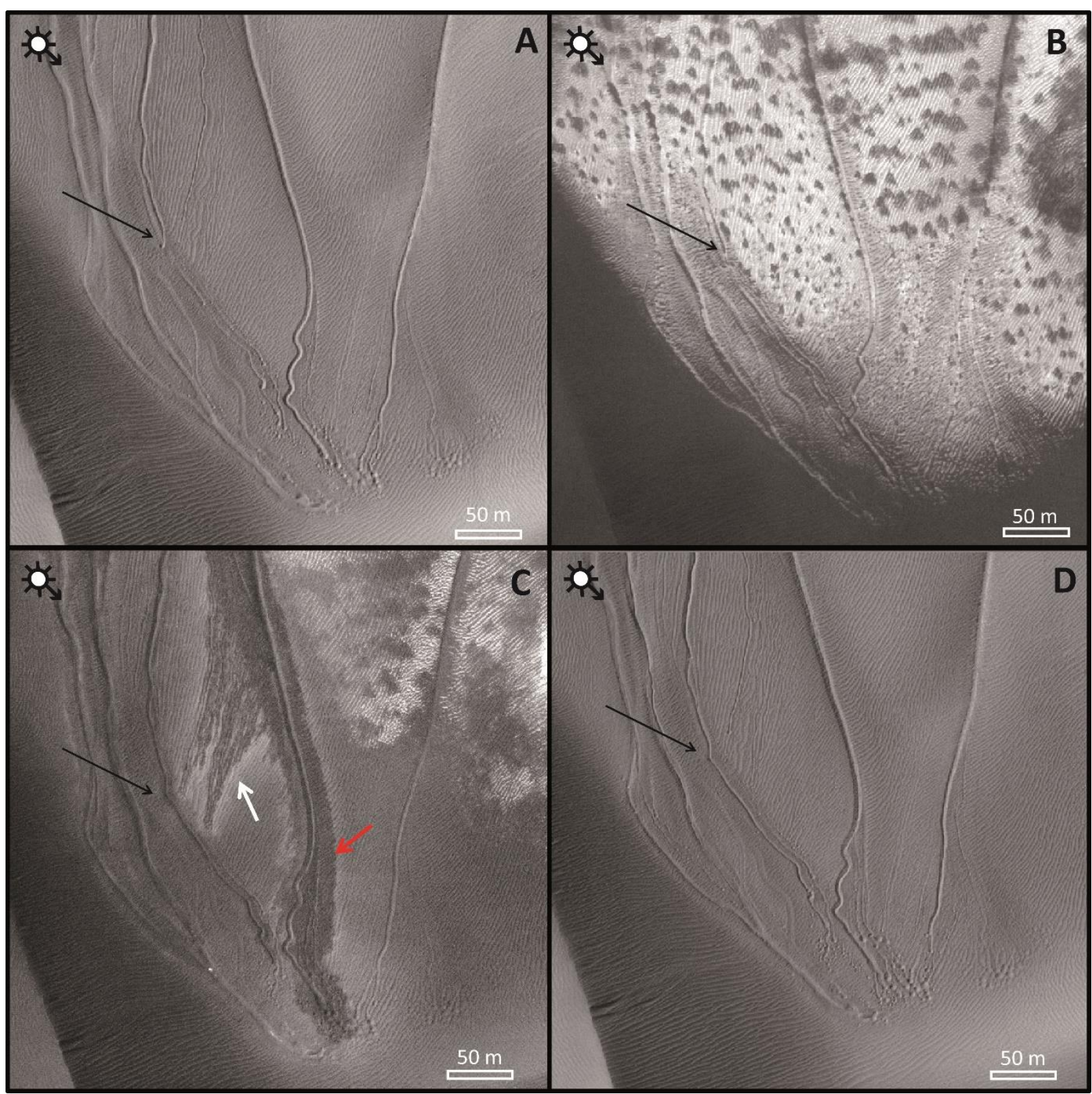

Fig. 5. The evolution of linear gullies and RDFs over one year on Matara crater dunefield. A) Linear 323 gullies and pits (MY30 Ls 208.8 ${ }^{\circ}$, HiRISE image ESP_020770_1300). B) High albedo frost coverage 324 and the appearance of dark spots due to defrosting (MY31 Ls: $165.4^{\circ} \mathrm{HiRISE}$ image 325 ESP_028616_1305). C) RDF (red arrow) and white halo (white arrow) with lengthening of some linear 326 gully channels (MY31 Ls: 183.7 , HiRISE image ESP_029038_1305). D) Final state at the end of 327 summer (MY31 Ls: 206.6 , HiRISE image ESP_029539_1305). The black arrow is a reference point, indicating the same location in each of the images. 

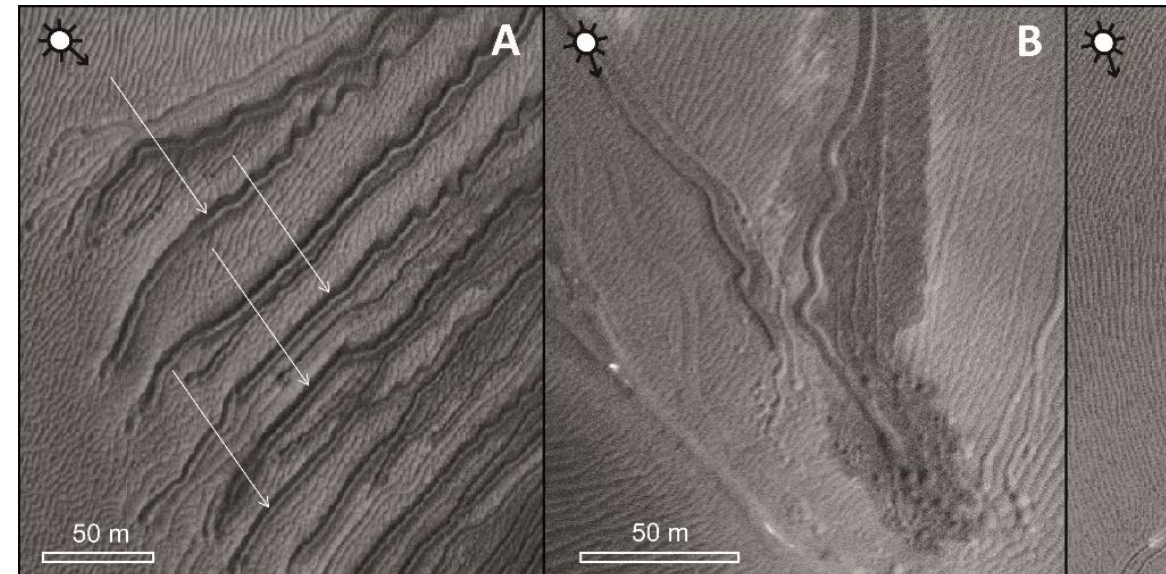

$50 \mathrm{~m}$

Fig. 6. RDF: A) An example of a RDF confined to the zone around linear gully channels indicated by white arrows. (HiRISE image: ESP_028488_1325). B) An example of a RDF that extends beyond linear gully channels (HiRISE image: ESP_029038_1305). C) An example of a RDF with a white halo (HiRISE image: ESP_028893_1320).

\subsection{Orientation}

The orientation of 357 linear gully sites was measured across the 6 selected intra-crater dunefields (Fig. 7). We find that sites with linear gullies generally face southwards (i.e. bearings between $90^{\circ}$ to $270^{\circ}$ ) and are most commonly oriented towards the south-southwest (with bearings between $150^{\circ}$ and $260^{\circ}$ ). In Rabe and Hellespontus Montes crater dunefields, sites with linear gullies have a more restricted range in orientation compared to the general population, with bearings between $180^{\circ}$ and $225^{\circ}$. There is no significant difference between the orientation of sites with active gullies and sites without active gullies. 

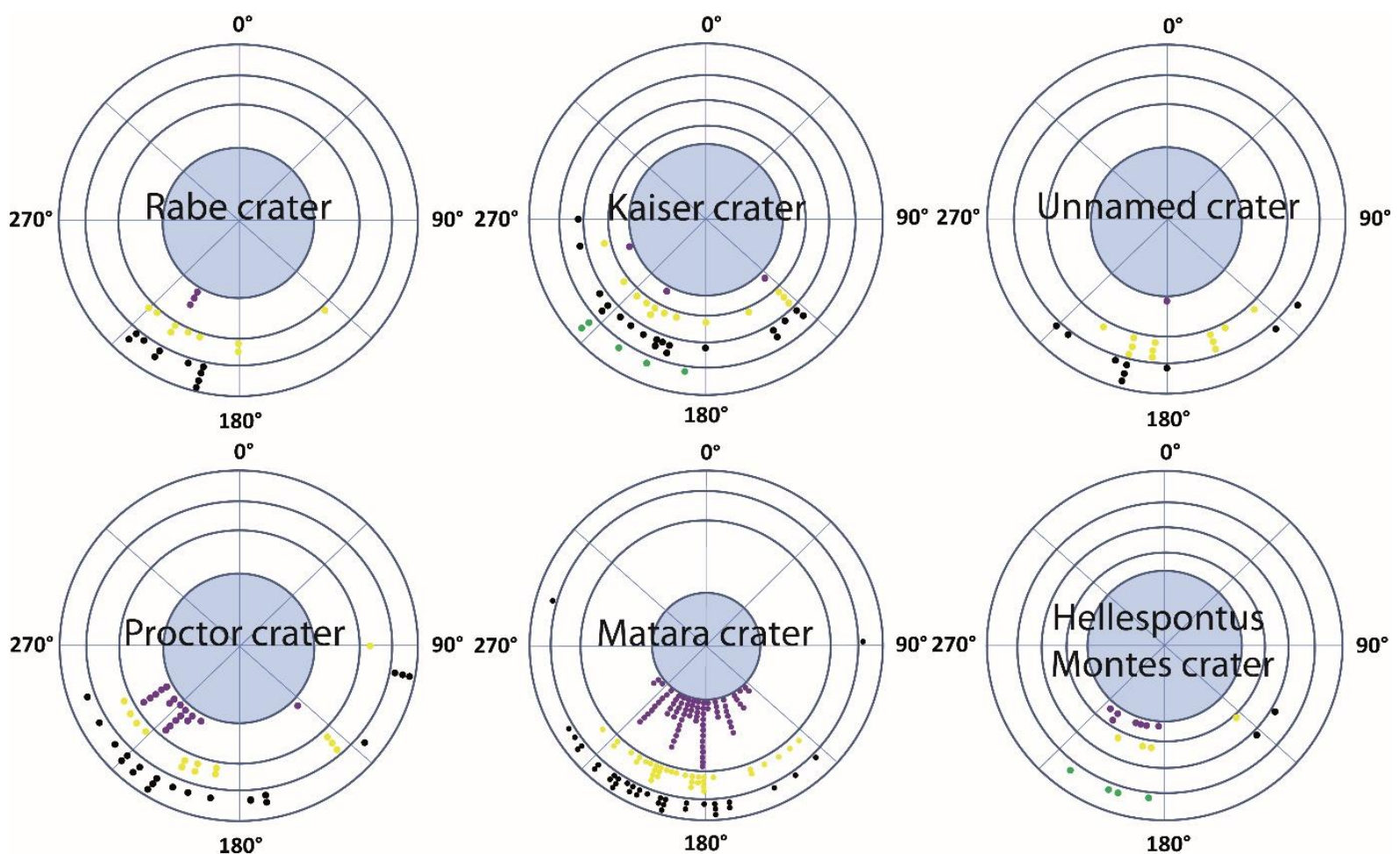

Fig. 7. Orientation of linear gully sites in the six study locations, given in bearings from due north, where a bearing of $180^{\circ}$ indicates that the dune-slope faces south. Each point represents a single linear gully site and each color represents the intensity of activity: purple = strong activity, yellow = low activity, black = no activity, green = uncertain activity. The activity index is defined in section 3.3. Measurements are reported in $5^{\circ}$ bins.

\subsection{Slopes}

We measured the slope angle of 34 sites which host active linear gullies and of 203 dunes with no linear gullies on Kaiser and Proctor crater dunefields. We find that the mean slope angle of sites with active linear gullies is $13.9 \pm 2.2^{\circ}$ for Proctor and $12.8 \pm 2.0^{\circ}$ for Kaiser (with a combined mean of $13.4 \pm 2.1^{\circ}$ ) (Fig. 8B). The slope angle just below the crest of the dune (measured over the top $20 \%$ of the duneprofile) has a mean of $20.6 \pm 3.4^{\circ}$ for sites with active linear gullies in Proctor and $20.0 \pm 1.7^{\circ}$ in Kaiser (with a combined mean of $20.3 \pm 2.8^{\circ}$ ) (Fig. 8A). For sites without linear gullies, we obtain a mean slope angle for the whole dune profile of $11.4 \pm 2.8^{\circ}$ for south-facing sites (Fig. 8D) and $14.4 \pm 4.9^{\circ}$ for north-facing sites (Fig. 8F). The mean slope angle just below the crest of the dune is $15.5 \pm 4.0^{\circ}$ for south-facing sites (Fig. $8 \mathrm{C}$ ) and $19.6 \pm 4.7^{\circ}$ for north-facing sites (Fig. 8E). We find that sites with active linear gullies are $4^{\circ}$ to $6^{\circ}$ steeper than south-facing sites without linear gullies. However there is no significant difference in slope angle between sites with active linear gullies and north-facing sites (which never host linear gullies). 

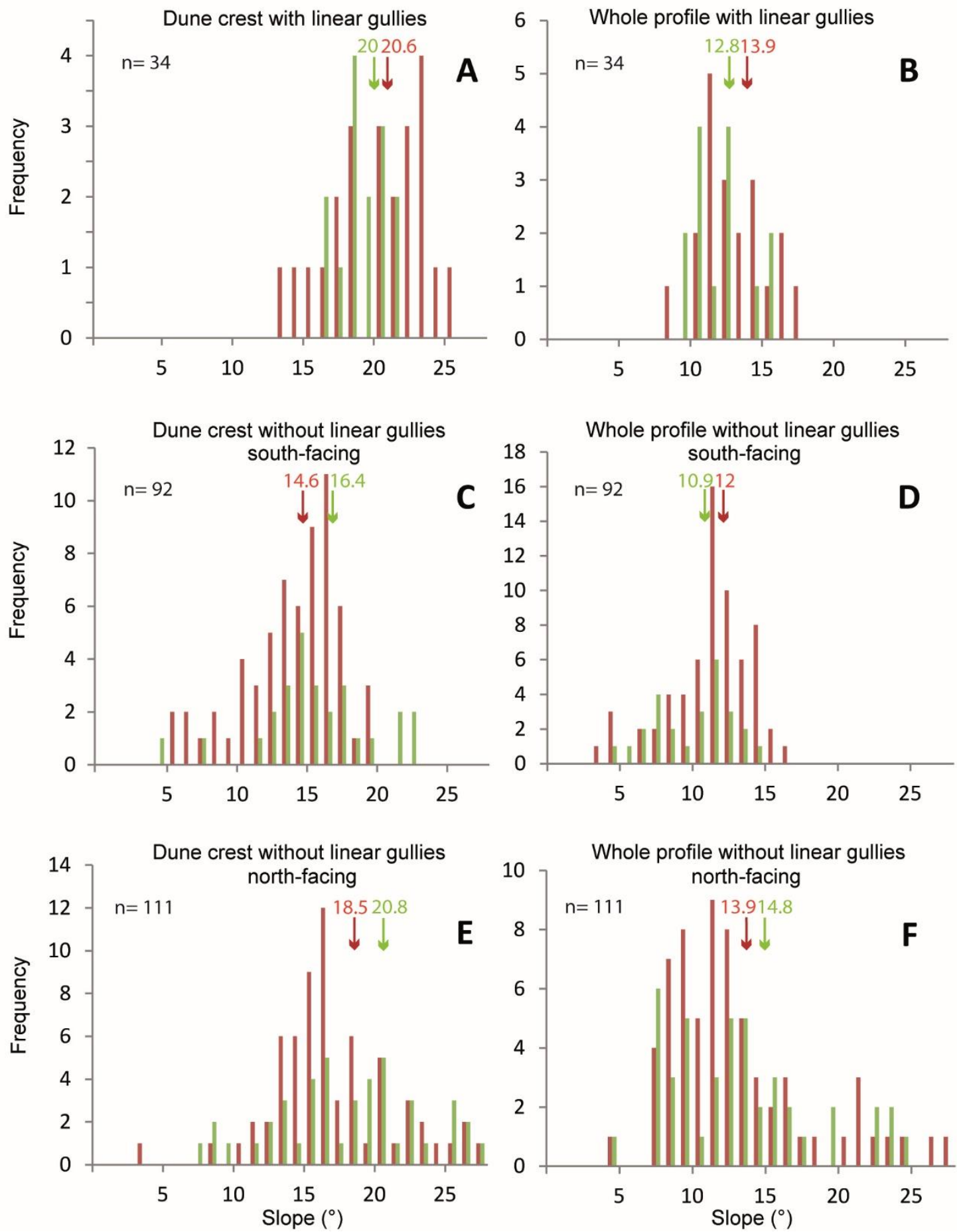

Fig. 8. Distribution of slope angles of sites in Proctor (red) and Kaiser (green) for sites with active linear gullies and for sites without linear gullies. "Dune crest" refers to measurements taken over the top $20 \%$ of the dune's profile and "Whole profile" refers to measurements taken over the whole dune profile. Arrows indicate the position of the mean (red: Proctor, green: Kaiser). Measurements are in $1^{\circ}$ bins, $n=$ number of sites included in the histogram and the $y$-axis label "frequency" signifies the number of measurements included per bin. 


\subsection{Seasonal evolution: timing of activity}

373

374

375

376

377

378

379

380

381

382

383

384

385

386

387

388

389

390

391

392

393

In order to better constrain the relative timing of linear gully activity (including channel-lengthening and new gully formation) and RDF appearance, repeat images spread over the seasons are required. Those two conditions are only fulfilled in three geographic areas: Matara, Kaiser and Hellespontus Montes dunefields. The results from our observations of repeat-images for these dunefields are presented in the following sections.

\subsubsection{Matara crater dunes fields $\left(49.5^{\circ} \mathrm{S}, 34.7^{\circ} \mathrm{E}\right)$}

46 HiRISE images cover Matara crater dunefields over the last 4 Martian years (MY29-32), with a better temporal coverage for the last 3 years. These images cover 125 linear gully sites, including 94 with active linear gullies, and 24 with RDF(s) (Table 2). We find that linear gully activity and RDF appearance are observed simultaneously at the end of winter and the beginning of spring, between Ls $167.4^{\circ}$ and Ls $216.6^{\circ}$ (Fig. 9A). RDFs are observed over a shorter timespan than active linear gullies. The RDFs appear at the same time as linear gullies are active at $L s$ $167.4^{\circ}$ and disappear again before Ls $206.6^{\circ}$ - a duration of 33-76 sols. All these RDFs have white halos visible between Ls $167.4^{\circ}$ and Ls $206.6^{\circ}$ (Fig. 9A).

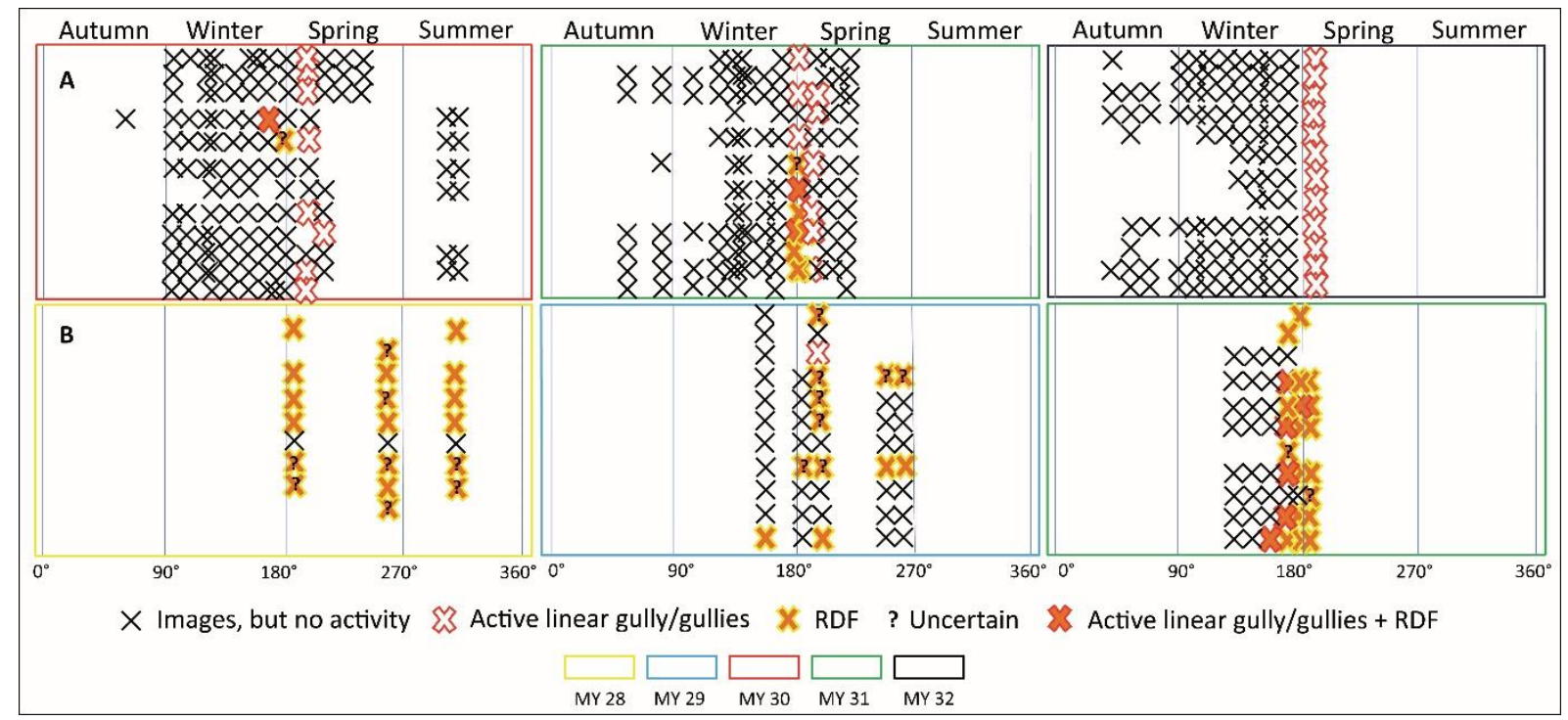

Fig. 9. The evolution of linear gullies and RDFs with season for: A) Matara crater dunefield during Martian years 30, 31 and 32 and B) Kaiser crater dunefield during Martian years 28, 29 and 31. Each horizontal line represents an individual linear gully site on the dunefield. The $x$-axis is time and is given in southern hemisphere season (top) and Ls (bottom). 
25 HiRISE images have been acquired covering the Kaiser crater dunefield over the last 4 Martian years (MY28-31), with the maximum number of image repeats occurring in MY31. There are 43 linear gully sites and we observe activity in 20 of them and RDFs in 28 of them (Table 2). We note no linear gully activity in Martian year 30 (where there is only one available image). Linear gully activity occurs in MY29 between Ls $155.8^{\circ}$ and Ls $198.7^{\circ}$ and in MY31 between Ls $155.1^{\circ}$ and Ls $179.0^{\circ}$ (Fig. 9B). For this dunefield there were no images that allowed us to constrain the timing of the disappearance of the RDFs. Only images taken in MY29 and MY31 show the appearance of RDFs, where they are first seen at the end of winter and continue to be visible in spring through to summer and disappear sometime between the end of summer and the middle of winter. RDFs are visible: during MY28 between Ls $158.9^{\circ}$ (first HiRISE image available) and Ls $310.9^{\circ}$; during MY29 between Ls $189.1^{\circ}$ and Ls $264.0^{\circ}$; during MY30 at Ls $197.2^{\circ}$ and finally; during MY31 between Ls $172.7^{\circ}$ and Ls $188.4^{\circ}$ (Fig. 9A). RDFs are visible for at least 332 sols, much longer than those on Matara dunefield. We do not observe any RDFs with white halo(s) around them, but this could be due to insufficient temporal sampling.

\subsubsection{Hellespontus Montes crater dunefields (52.2 $\left.{ }^{\circ} \mathrm{S} ; 2^{\circ} \mathrm{E}\right)$}

Hellespontus Montes crater dunefield is covered by only 5 images over 4 Martian years (MY28-31). We find 17 sites with linear gullies among which 15 were active and 12 had RDFs (Table 2). The number of images is inadequate to estimate the timing of the linear gully activity for each year individually. RDFs are visible during spring (at Ls $264.4^{\circ}$ (first image) in MY28; Ls $255.8^{\circ}$ in MY30) and the beginning of autumn (Ls $21.9^{\circ}$ in MY31). All sites where RDFs are visible at the end of spring (Ls

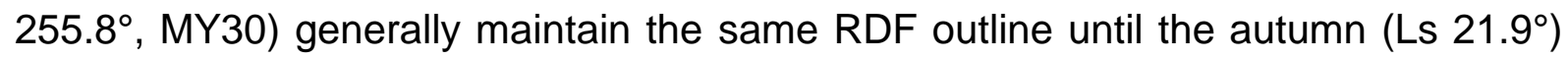
of the following year (MY31). We note two sites where the RDFs have white halos at the end of spring (Ls $\left.255.8^{\circ}\right)$. For the other RDF sites no white halo is observed.

\subsection{Albedo}

We find that the mean albedo of RDFs was $\sim 17 \%$ lower than the neighboring reference dune surface (Table 3), with a range between $2 \%$ and $39 \%$. In addition, for one site on HiRISE image ESP_029038_1305 we observe some very dark patches 
425 within the RDF, which were $48 \%$ darker than the reference dune surface (Fig. 10C). 426 These patches appear topographically below a series of linear gullies and are located 427 in an area which does not display any changes in the previous images (Figs. 10A,B). 428 On the following image (Fig. 10D) new pits appear where the dark patches occurred 429 antecedently.

\begin{tabular}{|c|c|c|c|c|c|}
\hline & $\begin{array}{c}\text { Site } \\
\text { number }\end{array}$ & HiRISE image & Ls $\left(^{\circ}\right)$ & MY & $\begin{array}{c}\text { Albedo difference } \\
(\%)\end{array}$ \\
\hline \multirow{7}{*}{ Matara } & 1 & ESP 0200581300 & 176.5 & 30 & 6 \\
\hline & 2 & ESP $029038 \quad 1305$ & 183.7 & 31 & 23 \\
\hline & 3 & ESP $029038 \quad 1305$ & 183.7 & 31 & 39 \\
\hline & 4 & ESP_029038_1305 & 183.7 & 31 & 18 \\
\hline & 5 & ESP $029038 \_1305$ & 183.7 & 31 & 2 \\
\hline & 6 & ESP_029038_1305 & 183.7 & 31 & 9 \\
\hline & 7 & ESP_019847_1300 & 167.4 & 30 & 34 \\
\hline \multirow{2}{*}{$\begin{array}{c}\text { Hellespontus } \\
\text { Montes }\end{array}$} & 1 & ESP_021733_1275 & 255.8 & 30 & 28 \\
\hline & 2 & ESP_021733_1275 & 255.8 & 30 & 12 \\
\hline \multirow[t]{7}{*}{ Kaiser } & 1 & ESP_028788_1325 & 172.7 & 31 & 18 \\
\hline & 2 & ESP_028788_1325 & 172.7 & 31 & 18 \\
\hline & 3 & ESP_028788_1325 & 172.7 & 31 & 23 \\
\hline & 4 & ESP_028933_1325 & 179 & 31 & 9 \\
\hline & 5 & PSP $004196 \quad 1325$ & 260.5 & 28 & 22 \\
\hline & 6 & ESP_013083_1325 & 264 & 29 & 14 \\
\hline & 7 & ESP 0205201325 & 197.2 & 30 & 12 \\
\hline \multirow[t]{5}{*}{ Proctor } & 1 & ESP $028893=1320$ & 177.3 & 31 & 10 \\
\hline & 2 & ESP_028814_1320 & 173.9 & 31 & 17 \\
\hline & 3 & PSP $003800 \quad 1325$ & 240.9 & 28 & 6 \\
\hline & 4 & ESP_030238_1325 & 240.4 & 31 & 12 \\
\hline & & & & Mean & $16.6( \pm 9.5)$ \\
\hline
\end{tabular}

430 Table 3. Relative albedo of RDFs compared to a reference dune surface for sites in 4 dunefields 431 (Matara, Hellespontus Montes, Kaiser and Proctor). Each line represents one site. 


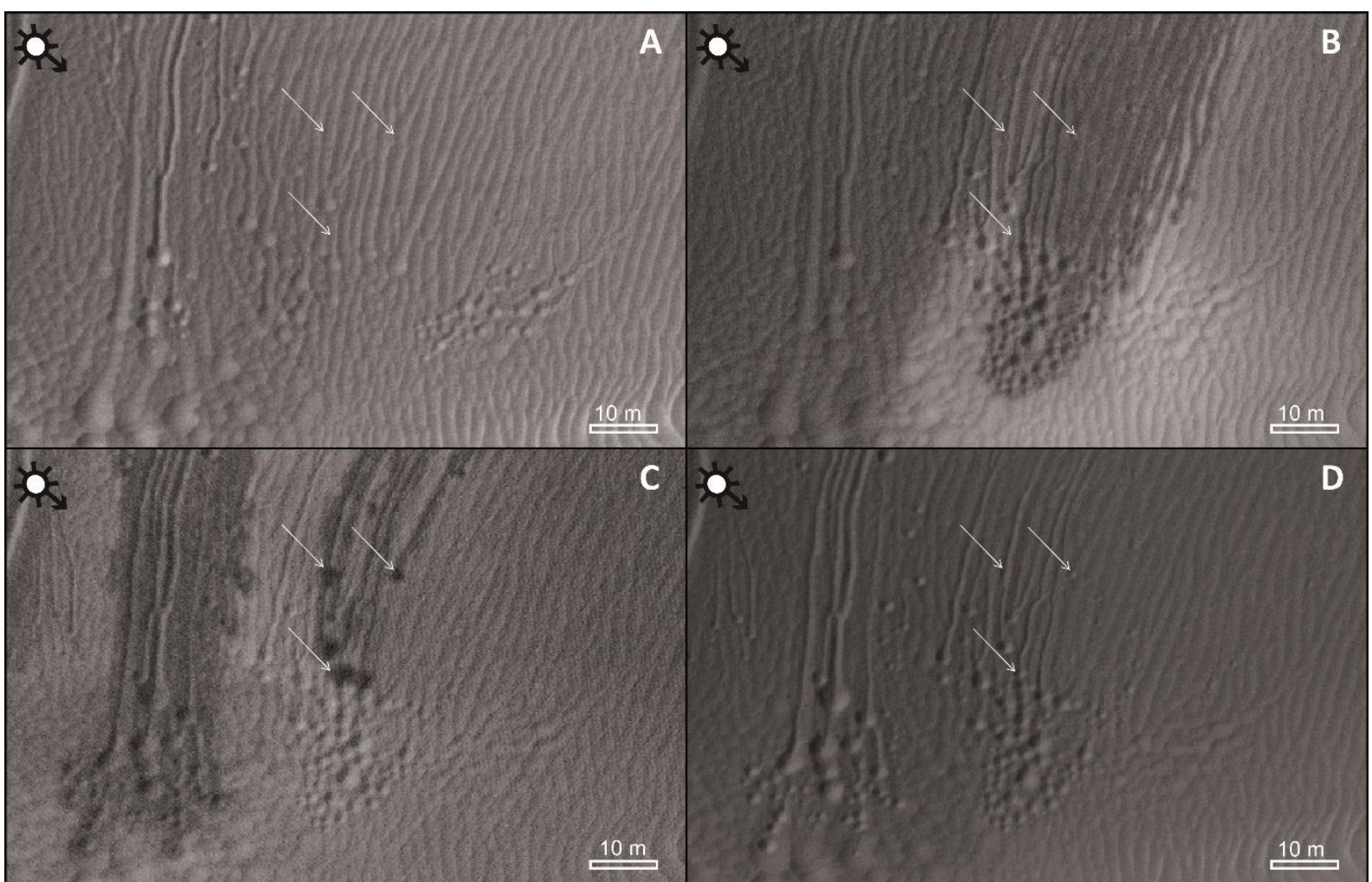

Fig. 10. Appearance of new pits on Matara crater dunefields in one Martian year. White arrows indicate the same positions for reference. A) Initial condition of the dune surface at MY30, Ls $208.8^{\circ}$ (Images HiRISE ESP_020770_1300). B) Appearance of RDFs in MY31 at Ls $180.8^{\circ}$ (Image HiRISE ESP_028972_1300). C) New RDF event with a different outline-shape and appearance of dark patches (indicated by white arrows) MY31 Ls: 183.7 (Image HiRISE ESP_029038_1305). D) New pits appear at the same location as occupied by the dark patches in the previous image (indicated by white arrows). MY31 Ls: 199.8 (Image HiRISE ESP_029394_1300).

\section{Discussion}

\subsection{Comparison with previous studies}

\subsubsection{Linear gully distribution}

Numerous studies of linear gullies have been undertaken over the last decade (e.g., Costard et al., 2002; Mangold et al., 2003 ; Reiss and Jaumann, 2003; Reiss et al., 2010; Dundas et al., 2012; Jouannic, 2012; Jouannic et al., 2012; Diniega et al., 2013). Many of these studies concerned the linear gullies of Russell megadune (Costard et al., 2002; Mangold et al., 2003; Reiss and Jaumann, 2003; Reiss et al., 2010; Jouannic, 2012; Jouannic et al., 2012; Dundas et al., 2012), but linear gullies have also been noted previously on Green, Kaiser, Matara, Proctor, Rabe and four unnamed dunefields (see Section 1.2 and Table 1 for coordinates and authors). We find an additional 23 dunefields where linear gullies occur; hence this gully-type is a lot more common than previously thought. 
Contrary to "classic" gullies (e.g., Malin and Edgett, 2000; Balme et al. 2006; Kneissl et al. 2010; Diniega et al. 2010; Harrison et al. 2015), the latitudinal distribution of linear dune gullies using HiRISE images has not been reported in the literature prior to this study. We find that linear dune gullies are concentrated between $36.3^{\circ} \mathrm{S}$ and $54.3^{\circ} \mathrm{S}$ and are occasionally found between $64.6^{\circ} \mathrm{S}$ and $70.4^{\circ} \mathrm{S}$ (Fig. 1A) in the southern hemisphere. This is broadly consistent with the latitudinal distribution of "classic" gullies (e.g., Harrison et al. 2015), however classic gullies start occurring $\sim 30^{\circ}$ and are most common at $\sim 35^{\circ}$. The lack of linear gullies at 30 $35^{\circ}$ could be due to the relative paucity of imaged dunefields in those latitudes (Fig. 1 ), rather than a different causative mechanism.

\subsubsection{Linear gully length and orientation}

Previous studies describing the size and orientation of linear gullies have mostly focused on the largest linear gullies found in the Russell crater dunefield, which are 2-2.5 km long (Mangold et al., 2003; Jouannic et al., 2012). However, these gullies are not necessarily representative of the general population of linear gullies. The mean length of the linear gullies located on Matara dunefield is $\sim 120 \mathrm{~m}$ (Fig. 4A) and we noted during our survey that this length is more typical for linear gullies, than the longer Russell linear gullies. This shorter mean length compared to the linear gullies on Russell crater, is likely due to the smaller size of the sand dunes investigated. The Russell megadune is of an exceptionally large size for martian dunes ( $500 \mathrm{~m}$ high, Jouannic et al., 2012), whereas the dunes in Kaiser crater are < $200 \mathrm{~m}$ high, which is more typical for martian sand dunes.

Our study confirms previous results regarding linear gully orientation, but with a larger and/or different dataset (Costard et al., 2002; Mangold et al., 2003; Reiss and Jaumann 2003; Balme et al., 2006; Reiss et al., 2010), namely that linear dune gullies are orientated southwards in the southern hemisphere. Here we show that gully orientations are concentrated between bearings of $150^{\circ}$ and $260^{\circ}$ using a dataset of $n=357$ on six different intra-crater dunefields (Fig. 7). We find no northwards-facing linear gullies. We infer that these observations are not just a simple artifact of the orientation of the dunes themselves, because these dunefields possess dunes with a wide range of different orientations (Hayward et al., 2007). 


\subsubsection{Linear gully slope}

The mean slope value for sites in our study with linear gullies $\left(\sim 13^{\circ}\right.$, Fig. 8$)$ is slightly higher than the $\sim 10^{\circ}$ slope value estimated for linear gullies on the Russell megadune by Mangold et al. (2003) and Jouannic et al. (2012), using MOLA and HiRISE DTM data, respectively. Jouannic et al. (2012) found that only a small area located under the dune crest had a slope higher $20^{\circ}$ on the Russell megadune and the dunes with linear gullies in our study have slope values $\sim 20^{\circ}$ just below the crest (Fig. 8).

However, our study is the first to compare the slope angles of dunes with and without linear gullies and we find that the crest-slopes of south-facing dunes are steeper when linear gullies are present (Fig. 8). We also find that north-facing duneslopes (which never host linear gullies) are steeper than south-facing ones without linear gullies. These results have three possible implications, first that the process forming linear gullies requires steeper slopes to be active, second that the process itself results in steeper slopes, and/or third that the process results in progressively gentler slopes that finally inhibit the process. If the first, then the fact that north-facing dune slopes have similar slope angles to south-facing ones hosting gullies, supports our inference that the orientation trends we observe are not a function of the initial dune orientation.

\subsubsection{Linear gully activity and timing}

Compared to previous studies, we have detected and characterized numerous ( $n=\sim 353$ ) new active sites of linear gullies in the Matara, Proctor, Rabe, Kaiser, Unnamed $\left(47.2^{\circ} \mathrm{S}, 34^{\circ} \mathrm{E}\right)$, and Hellespontus Montes craters. On Matara, Kaiser and Unnamed $\left(47.2^{\circ} \mathrm{S}, 34^{\circ} \mathrm{E}\right)$ dunefields only a few $(n=\sim 4)$ active linear gullies had previously been reported (Mangold et al., 2003; Diniega et al., 2013), but had not been systematically analyzed. Further, we find that in $23 \%$ of our sites $(n=82)$ this activity is "strong" (i.e. creation or the lengthening of at least 3 linear gullies in the same site in one Martian year; Fig. 7).

Reiss and Jaumann (2003) estimated Russell crater linear gullies to be active during summer and Reiss et al. (2010) report they are active during spring between Ls $198^{\circ}$ and Ls $218^{\circ}$. Dundas et al. (2012) estimated that linear gullies were active in Unnamed crater $\left(49^{\circ} \mathrm{S}, 27.2^{\circ} \mathrm{E}\right)$ between Ls $179^{\circ}$ and Ls $195^{\circ}$. Our observations 
constrain the timing of linear dune gully activity on multiple dunefields for multiple years, to between Ls $167^{\circ}$ and Ls $216^{\circ}$ in the southern hemisphere and therefore, strengthen the link between this activity and seasonal defrosting processes. Due to the restricted latitudinal area over which we studied linear gullies, we were not able to observe any trends in the timing of the activity of linear gullies with latitude.

\subsection{Summary of new findings}

\subsubsection{Linear gully degradation}

Our detailed study of linear gullies on 6 intra-crater dunefields shows that their channels fade in only a few years after their creation if they are not reactivated (Fig. 3). In general, dunes on Mars are known to be active systems, with previous studies reporting ripple migration (Gardin et al., 2010), dark flows (Möhlmann and Kereszturi, 2010) and dust devil tracks (Verba et al., 2010). All these factors may influence the longevity of landforms on dunes. Only linear gullies $<150 \mathrm{~m}$ infilled and faded during the period covered by our HiRISE observations, but it is likely that over longer time periods larger linear gullies, such as those on the Russell megadune could also begin to be erased.

\subsubsection{Linear gullies and RDF}

The consistent relative timing and spatial occurrence of linear gully activity and RDF appearance across multiple dunefields (with similar latitude) and over several Martian years suggests a causal link. Notably the appearance of RDF generally precedes, or coincides with the activity of linear gullies and they never appear after the activity of linear gullies has started. Secondly, the appearance of RDF can lead to the formation of darker patches which directly precede the appearance of new pits. The persistence of RDF after the activity of linear gullies has stopped suggests one of two hypotheses: (i) The surface expression of RDF that occurs in late winter/early spring simply persists between image-observations or (ii) the RDF disappears and then reappears again during spring and summer. Our data do not allow us to distinguish between these alternatives. 


\subsection{Possible formation process}

\subsubsection{Wind and dry processes}

Our work shows that linear gullies are constrained in latitude and in orientation. If linear gullies were a result of gravity-driven granular processes on dunes then such latitudinal and orientation constraints would not be expected, because such processes would be expected on all dunes independent of latitude/orientation. In particular linear gullies consistently occur on S-, to SW-facing dune slopes, even when these are not the primary orientations of the dunes themselves, suggesting they are not linked with prevailing wind directions. Linear gullies do not align perpendicular to ripples (Figs. $5 ; 6 ; 10$ ), which might also be the case if they were triggered by winds. We have shown that this orientation bias is not just an artefact of dune morphology; north-facing dune slopes without linear gullies are just as steep as south-facing ones with linear gullies. In addition the $\sim 20^{\circ}$ slope angle at which linear gullies originate is below the internal friction angle of sand, which is approximately $25-30^{\circ}$ on Earth and $30-37^{\circ}$ on Mars (Kleinhans et al., 2011; Sullivan et al., 2011).

Other workers have also made morphological arguments against aeolian and/or dry processes for forming linear gullies, including the presence of: sinuosity, levees (Mangold et al., 2010) (Figs. 2A,B) and tributary channel networks (Jouannic et al., 2015). Our observations support the conclusions of previous work, which find dry and/or aeolian processes inadequate to explain the formation of linear gullies.

\subsubsection{High obliquity and insolation}

The fact that the latitudinal distribution and orientation of linear dune gullies is similar to that reported in previous studies of "classic" gullies (see Sections 4.1.1 and 4.1.2) initially points to a common formation mechanism. The observed trend in latitude and orientation of classic gullies has been linked to insolation patterns under high obliquity (e.g., Costard et al., 2002; Balme et al., 2006; Kreslavsky et al., 2008). The ability to accumulate and melt ice on south-facing slopes in the mid-latitudes is favored at obliquity $>30^{\circ}$, hence the adoption of this theory to explain the formation of classic gullies by flowing water several million years ago. Insolation patterns also control the deposition and sublimation of $\mathrm{CO}_{2}$ on slopes and therefore the latitudinal 
575 distribution and orientation of gullies is also considered to be consistent with this mechanism under high obliquity conditions (Pilorget and Forget, 2015).

However, the observation of abundant seasonal activity presented in this study, in Reiss et al. (2010), Dundas et al. (2012) and Diniega et al. (2013), combined with our finding that these features suffer rapid degradation, shows that linear gullies are young features and cannot be relict features left over from previous obliquity cycles (Laskar et al., 2004).

\subsubsection{Relative timing of seasonal frosts, linear gully activity and RDF appearance}

The fact remains that linear gullies are restricted in latitude and in orientation, and only lengthen at certain times in the year, which still points to a climate-related formation mechanism. For the six sites we studied in detail (spanning $43-52^{\circ} \mathrm{S}$ ), the year-maximum day-average insolation for sloping surfaces is experienced on polefacing slopes (Kreslavsky et al., 2008), corresponding with the orientation of these linear gullies. Conversely equator-facing slopes receive maximum insolation at latitudes of $\sim 0-45^{\circ} S$ and $\sim 60-90^{\circ} S$, however the orientation of linear gullies located in these zones does not change from those in our six principal study sites. This lack of correlation between maximum insolation and linear gully orientation suggests that deposition and preservation of volatiles might be a more important factor in controlling the distribution of linear gullies.

The seasonal $\mathrm{CO}_{2}$ polar cap commonly extends to latitudes of $\sim 50^{\circ}$ and on steep pole-facing slopes seasonal deposition of $\mathrm{CO}_{2}$ ice has been observed to latitudes as low as $34^{\circ} \mathrm{S}$ (Vincendon et al. 2010b). Thus the latitudinal extent of the $\mathrm{CO}_{2}$ ice associated with the seasonal polar cap seems to fit with the latitudinal distribution and orientation of linear gullies, suggesting a possible link.

As discussed in Section 2.2, we could not use spectral data to determine whether $\mathrm{CO}_{2}$ ice was present for any given observation. We therefore relied on the presence of secondary features to evaluate the presence or absence of $\mathrm{CO}_{2}$ ice. Bright frost (Fig. 5B) is observed every winter on 4 of the 6 studied dunefields (Matara, Kaiser, Unnamed $\left(47.2^{\circ} \mathrm{S}, 34^{\circ} \mathrm{E}\right)$ and Proctor craters). For the other dunefields (Hellespontus Montes and Rabe crater), there are no available images in winter. Bright frost is always associated with the appearance of dark spots and dark flows in spring and these features are only observed on certain pole-facing slopes. 
Dundas et al, (2012) and Diniega et al. (2013) noted that linear gullies are only

608 present on slopes where bright frost occurs in winter and particularly where frost remains longer - our observations confirm this. However, dunes with frost do not systematically possess linear gullies. In order to assess the relative timing of frost occurrence, RDF appearance and linear gully activity, we examined images of Matara and Kaiser craters, which provide the tightest constraints as they have better temporal coverage of HiRISE images. For Matara crater dunefield, frost is observed: from the middle of autumn (Ls 49.1 ${ }^{\circ}$ ) through the beginning of the winter (Ls 92.9) to the end of winter/beginning of spring (Ls $176.5^{\circ}$ and Ls 183.7 $)$. For Kaiser crater dunefield, frost is observed: from the end of autumn (Ls $85.4^{\circ}$ ) to the end of winter (Ls $\left.179^{\circ}\right)$. Similarly Gardin et al. (2010) found that $\mathrm{CO}_{2}$ ice on Russell crater dunes had disappeared by Ls $197^{\circ}$. Our observations show that the activity of linear gullies and appearance of RDF occur towards the end of the defrosting period (Fig. 11). In several cases $(n=24)$ RDF source areas are located in the middle of an area still covered by $\mathrm{CO}_{2}$ frost.

The deposition of the seasonal frost is poorly observed on Mars, because the imaging conditions are not favorable, they coincide with the polar night and intense cloud activity and therefore we have poor temporal constraint on the timing of frost deposition.

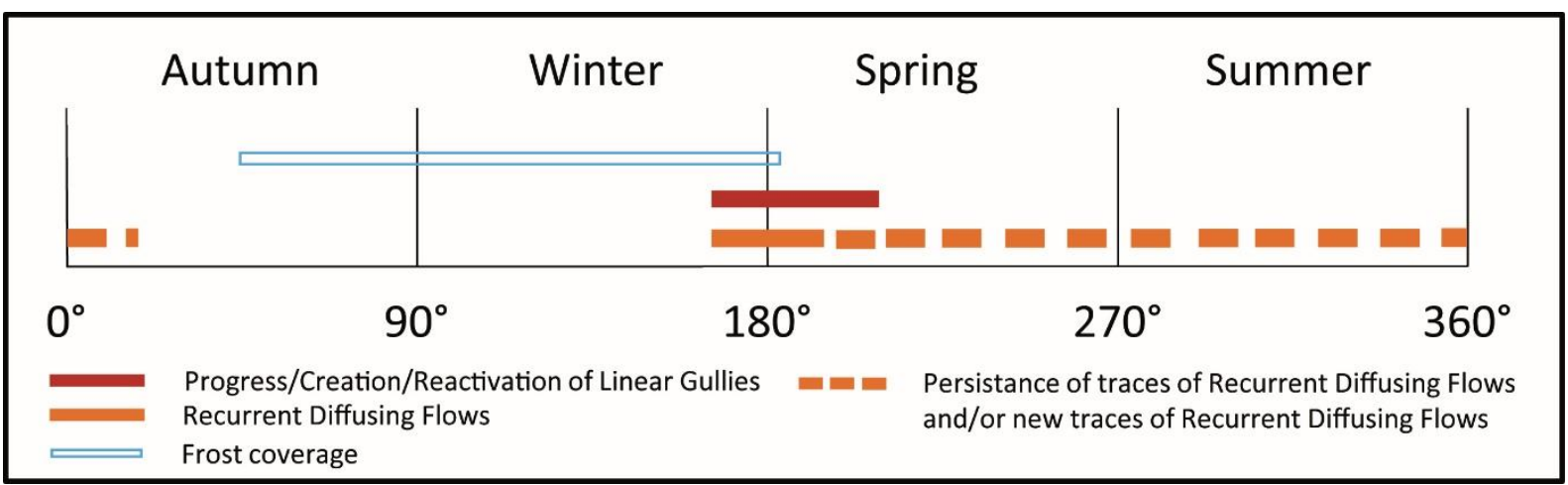

Fig. 11. Summary of observations on the seasonal evolution of linear gully activity, RDF and frost occurrence. This synthesis is derived from the observations in Rabe, Kaiser, Unnamed $\left(47.2^{\circ} \mathrm{S}, 34^{\circ} \mathrm{E}\right)$, Proctor, Matara and Hellespontus Montes crater dunefields.

\subsubsection{Defrosting processes}

As reviewed briefly in Section 1.4, defrosting processes associated with the sublimation of seasonal $\mathrm{CO}_{2}$ ice has been linked to the formation of dark spots and flows on dunes (Kieffer et al., 2000, 2006; Piqueux et al., 2003; Kieffer, 2007; Piqueux and Christensen, 2008). These morphologies have little topographic effect, 
hence cannot be directly linked to the topographic changes in linear gullies found in this and previous studies. The detachment of blocks of $\mathrm{CO}_{2}$ ice from the crest of the dune and their subsequent downslope sliding has been proposed as a formative mechanism for linear gullies (Dundas et al., 2012; Diniega et al., 2013). The stagnation and the sublimation of these blocks is hypothesized to result in the formation of terminal pits. Previous studies have noted the occurrence of bright patches, interpreted to be the residue of these $\mathrm{CO}_{2}$ blocks, within some pits (Dundas et al., 2012; Diniega et al., 2013). Using this block-sliding-mechanism alone, it is difficult to explain: the timing of linear gully lengthening (towards the end of the defrosting period, when $\mathrm{CO}_{2}$ frost would be less likely to form slabs), the large areal extent and digitate-shape of RDF, and the occurrence of unconnected terminal pits (Figs. 2H,I).

Sublimation of $\mathrm{CO}_{2}$ ice has, however, been associated with meter-scale topographic changes associated with "classic" mid-latitude gullies (Vincendon, 2015). The feasibility of this process as an agent of topographic change has been suggested by recent laboratory experiments which showed that small amounts of $\mathrm{CO}_{2}$ frost deposited into a granular medium can cause granular flows on slopes $>13^{\circ}$ under terrestrial gravity (Sylvest et al., 2016). Consistent with these laboratory findings, which suggest sediment mobilization by $\mathrm{CO}_{2}$ sublimation is slope limited, our study highlights that it is only the steepest dune slopes that possess active linear gullies (Fig. 8). Unconnected terminal pits might be formed by $\mathrm{CO}_{2}$ gas escaping as a result of subsurface $\mathrm{CO}_{2}$ ice sublimation, which would be expected to occur late in the defrosting period. The white halo around RDFs could therefore correspond to refreezing of $\mathrm{CO}_{2}$ onto the surface. However, the detailed thermal models required in order to substantiate these hypotheses are beyond the scope of this paper.

In summary, the spatial coincidence of seasonal $\mathrm{CO}_{2}$ frost and linear gullies combined with the consistent timing of linear gully lengthening and RDF appearance within the annual $\mathrm{CO}_{2}$ defrosting cycle point to a possible causal link. However, it is not known whether this $\mathrm{CO}_{2}$ sublimation mechanism can mobilize sufficient sediment to produce these landforms, or whether it can produce the sinuous, tributary and leveed channels observed in linear gullies. To resolve these unknowns will require more detailed monitoring and more empirical data on sediment transport by martian $\mathrm{CO}_{2}$ sublimation-defrosting processes. 


\subsubsection{Could water be playing a role?}

669

670

671

672

673

674

675

676

677

678

679

680

681

682

683

684

685

686

687

688

689

690

691

692

693

694

695

696

697

698

699

700

Previous workers have suggested that liquid water could be playing a role in the formation of linear gullies (Costard et al., 2002; Mangold et al., 2003; Reiss and Jaumann, 2003; Reiss et al., 2010). The flow of liquid water or brines is invoked because such fluids are able to reproduce some of the complex morphologies of linear gullies, such as leveed channels, tributary networks, perched channels and sinuosity (Costard et al., 2002; Mangold et al., 2003; 2010; Jouannic et al., 2012; 2015). Two of our findings also point towards a potential role of liquid water (or brines): first the late activity of linear gullies within the defrosting period and second the observation of dark patches preceding the appearance of new terminal pits.

Temperature analysis with TES instrument (Thermal Emission Spectrometer) on the Russell mega-dune $\left(54.3^{\circ} \mathrm{S}, 13^{\circ} \mathrm{E}\right)$, which is at a similar latitude to our six study sites, shows that a temperature of $273 \mathrm{~K}$ is reached between Ls $215^{\circ}-\mathrm{Ls} 230^{\circ}$ (Reiss et al, 2010; Reiss and Jaumann, 2003) - just after the period where we find linear gully lengthening and the appearance of RDF (Figs. 9; 11). These abovefreezing temperatures have a duration of only few hours per day and the thermal wave penetrates only a few millimeters into the ground (Mellon and Jakosky, 1993). Therefore, although pure water cannot be involved a salt-rich aqueous solution could be liquid at these temperatures (Knauth and Burt, 2002; Chevrier and Altheide, 2008; Reiss et al., 2010). The potential for such salt-rich aqueous solutions to exist on the surface of Mars has been suggested through the observation of their hydrated spectral signature at four RSL (Recurring Slope Lineae) sites in the northern hemisphere (Ojha et al., 2015) and at the foot of the Russell megadune (John Carter, personal communication).

A second, more tentative line of evidence, is the albedo decrease of $48 \%$ that we observe prior to the formation of new pits on the Matara crater dunefield (Fig. 10C). This magnitude of albedo decrease is similar to that observed for RSL (Ojha et al., 2015; McEwen et al., 2011), which is thought to be caused by the presence of liquid water, or brine. For comparison, dust devil tracks, which are known to darken the surface by simply removing a layer of dust, have an average difference in albedo compared to the reference surface of about 20\% (Statella et al., 2015). Massé et al. (2014) demonstrate that the presence of intergranular liquid water (or brine) can lead to an albedo decrease of $30-40 \%$. Although a liquid brine is 
consistent with the morphology, timing and albedo observations, there are numerous problems associated with generating this liquid, as summarized in papers concerning RSL (McEwen et al., 2014; Stillman et al., 2014; Ojha et al., 2015).

Under current conditions, the potential sources of water ice to generate melt include: (1) seasonal deposition of surface frost which can be 2-200 microns thick at latitudes down to $13^{\circ}$ in the southern hemisphere (Vincendon et al., 2010b), or (2) a water ice-rich permafrost in the subsurface formed during high obliquity periods (Costard et al., 2002; Mischna et al., 2003; Williams et al., 2009; Head et al., 2010; Vincendon et al., 2010a; Dickson et al., 2012). Generating melt from either of these sources is thought to be difficult. Surface frost sublimates before it can melt (McEwen et al., 2014; Stillman et al., 2014; Ojha et al., 2015) and the annual thermal wave does not theoretically penetrate deep-enough to reach the ice-rich permafrost table (Mellon and Jakosky, 1993). When considering brines, there are the additional problems of salt-recharge and insufficient atmospheric humidity for deliquescence (McEwen et al., 2014; Stillman et al., 2014; Ojha et al., 2015). An in-depth analysis of melt-generation is beyond the scope of this paper, however we note that a causal link between present-day linear gully activity and a subsurface ice-rich permafrost can neither be established, nor excluded.

\section{Conclusions}

We present the results of the first systematic survey of linear dune gullies in the southern hemisphere of Mars and an in-depth study of the timing of linear gully activity in six of those dunefields. From our survey we find:

- Linear dune gullies are found in two latitudinal zones: 1) primarily between $36.3^{\circ} \mathrm{S}$ and $54.3^{\circ} \mathrm{S}$ and 2) occasionally between $64.6^{\circ} \mathrm{S}$ and $70.4^{\circ} \mathrm{S}$.

- We find 33 dunefields with linear dune gullies, 23 more than previously reported, showing they are more common than previously thought.

From our detailed study of six of these sites (all located between $43^{\circ} \mathrm{S}$ and $52^{\circ} \mathrm{S}$ ) we find:

- Linear gullies are "active" at the present-day, including (1) appearance of new linear gullies, (2) lengthening of existing channels, (3) complete or partial reactivation, and (4) disappearance of gullies. Gullies lengthen by $\sim 100 \mathrm{~m}$ per year and importantly just over half of the sites with linear gullies have such activity, with $\sim 1 / 4$ having the lengthening of 3 or more channels. 
- This abundant recent activity and the rapid disappearance of linear gullies argues against the hypothesis that these are remnant morphologies left over from previous periods of high obliquity millions of years ago.

- The activity of linear gullies is temporally and spatially associated with "Recurrent Diffusing Flows" (RDF), which are lower albedo patches encompassing the active gully areas. Linear gullies are active between the end of winter (Ls 167.4 ) and the beginning of spring (Ls 216.6 ${ }^{\circ}$ ) and RDFs appear from the end of winter (Ls $167.4^{\circ}$ ) to the beginning of autumn (Ls 21.9').

- Linear gullies only occur on S- to SSW-facing slopes of dunes - which corresponds to the location of seasonal $\mathrm{CO}_{2}$ ice deposits. Gully activity and RDF occur towards the end of the $\mathrm{CO}_{2}$ defrosting period. Linear gullies are not observed on all S-SSW-facing frost covered dune slopes, but only those where the slope just below the crest is $\sim 20^{\circ}$, suggesting a slope-limited process involving $\mathrm{CO}_{2}$ sublimation.

Our observations do not provide definitive evidence in favor of either $\mathrm{CO}_{2}$ sublimation processes or water/brine processes for the formation of linear dune gullies. They do however provide a wealth of temporal and morphometric constraints that can be used to undertake numerical modelling, to direct future image monitoring and to guide laboratory experiments, which can be used to constrain the formation process of these enigmatic features.

\section{Acknowledgments}

This study is supported by the PNP (Programme National de Planétologie), CNRS/CNES, France. We thank the two anonymous reviewers for their advice and useful comments. We want to thank too Chiara Marmo for her help on the albedo study.

\section{References}

Balme, M., Mangold, N., Baratoux, D., Costard, F., Gosselin, M., Masson, P., Pinet, P., Neukum, G. 2006. Orientation and distribution of recent gullies in the southern hemisphere of Mars: Observations from High Resolution Stereo Camera/ Mars Express (HRSC/MEX) and Mars Orbiter Camera/Mars Global Surveyor (MOC/MGS) 
data. J. Geophy. Res. (Planets), $111 \quad$ (E5). http://dx.doi.org/ 765 10.1029/2005JE002607E5.

766 Bandfield, J.L., 2002. Global mineral distributions on Mars. J. Geophy. Res. Planets 767107 (E6), 5042. http://dx.doi.org/10.1029/2001JE001510.

768 Chevrier, V., Altheide, T., 2008. Low temperature aqueous ferric sulfate solutions on 769 the surface of Mars, J. Geophy. Res. Lett. 35, L22101. 770 http://dx.doi.org/10.1029/2008GL035489.

771 Costard, F., Forget, F., Mangold, N., Peulvast, J.P., 2002. Formation of recent 772 Martian debris flows by melting of near-surface ground ice at high obliquity. Planet. 773 Sci. 295, 110-113. http://dx.doi.org/10.1126/science.1066698.

774 Daubar, I.J., McEwen, A.S., Golombek. M.P., 2015. Albedo changes at Martian 775 landing sites. Lunar Planet. Sci. 46. Abstract 2225.

776 Di Achille, G., Silvestro, S., Ori, G.G., 2008. Defrosting processes on dark dunes: 777 new insights from HiRISE images at Noachis and Aonia Terrae, Mars. In: Planetary 778 Dunes Workshop, pp. 27-28.

779 Dickson, J.L., Head, J.W., Fassett, C.I., 2012. Patterns of accumulation and flow of 780 ice in the mid-latitudes of Mars during the Amazonian. Icarus 219, 723-732. 781 http://dx.doi.org/10.1016/j.icarus.2012.03.010.

782 Diniega, S., Byrne, S., Bridges, N.T., Dundas, C.M., McEwen, A.S., 2010. 783 Seasonality of present-day martian dune-gully activity. Geology 38, 1047-1050. 784 http://dx.doi.org/10.1130/G31287.1.

785 Diniega, S., Hansen, C.J., McElwaine, J.N., Hugenholtz, C.H., Dundas, C.M., 786 McEwen, A.S., Bourke, M.C., 2013. A new dry hypothesis for the formation of Martian 787 linear gullies. Icarus 225, 526-537. http://dx.doi.org/10.1016/j.icarus.2013.04.006.

788 Dundas, C.M., Diniega, S., Hansen, C.J., Byrne, S., McEwen, A.S., 2012. Seasonal 789 activity and morphological changes in Martian gullies. Icarus 220, 124-143. 790 http://dx.doi.org/ 10.1016/j.icarus.2012.04.005. 
791 Dundas, C.M., Diniega, S., McEwen, A.S., 2015. Long-term monitoring of martian 792 gully formation and evolution with MRO/HiRISE. Icarus 251, 244-263. http://dx.doi.org/10.1016/j.icarus.2014.05.013.

794 Dundas, C.M., McEwen, A.S., Diniega, S., Byrne, S., Martinez-Alonso, S., 2010. New 795 and recent gully activity on Mars as seen by HiRISE. Geophys. Res. Lett. 37, L07202. http://dx.doi.org/10.1029/2009GL041351.

797

798

799

800

801

802

803

804

805

806

807

808

809

810

811

812

813

814

815

816

817

818

819

Fenton, L.K., Hayward, R.K., 2010. Southern high latitude dunefields on Mars: morphology, aeolian inactivity, and climate change. Geomorphology 121, 98-121. http://dx.doi.org/10.1016/j.geomorph.2009.11.006.

Gardin, E., Allemand, P., Quantin, C., Thollot, P., 2010. Defrosting, dark flow features, and dune activity on Mars: Example in Russell crater. J. Geophys. Res. 115, 1-9. http://dx.doi.org/10.1029/2009JE003515.

Hansen, C.J., Bourke, M., Bridges, N.T., Byrne, S., Colon, C., Diniega, S., Dundas, C., Herkenhoff, K., McEwen, A., Mellon, M., Portyankina, G., Thomas, N.2011. Seasonal erosion and restoration of Mars' northern polar dunes. Science 331, 575578. http://dx.doi.org/10.1126/science.1197636.

Harrison, T.N., Osinski, G.R., Tornabene, L.L., Jones, E., 2015. Global documentation of gullies with the Mars Reconnaissance Orbiter Context Camera and implications for their formation. Icarus 252, 236-254. http://dx.doi.org/10.1016/j.icarus.2015.01.022.

Hayward, R.K., Fenton, L.K., Titus, T.N., 2014. Mars Global Digital Dune Database (MGD3): Global dune distribution and wind pattern observations. Icarus 230, 38-46. http://dx.doi.org/10.1016/j.icarus.2013.04.011.

Hayward, R.K., Mullins, K.F., Fenton, L.K., Hare, T.M., Titus, T.N., Bourke, M.C., Colaprete, A., Christensen, P.R., 2007. Mars Global Digital Dune Database and initial $\begin{array}{lllllll}\text { science results. J. Geophys. Res. } 112 & \text { (E11), } 007 .\end{array}$ http://dx.doi.org/10.1029/2007JE002943.

Head, J.W., Marchant, D.R., Dickson, J.L., Kress, A.M., Baker, D.M., 2010. Northern mid-latitude glaciation in the late Amazonian period of Mars: Criteria for the 
820 recognition of debris-covered glacier and valley glacier landsystem deposits. Earth 821 Planet. Sci. Lett. 294, 306-320.

822 Herkenhoff, K.E., Vasavada, A.R., 1999. Dark material in the polar layered deposits 823 and dunes on Mars. J. Geophys. Res. 104 (E7), 16487-16500. 824 http://dx.doi.org/10.1029/1998JE000589.

825 Hugenholtz, C.H., Wolfe, S. a., Moorman, B.J., 2007. Sand-Water Flows on Cold826 Climate Eolian Dunes: Environmental Analogs for the Eolian Rock Record and Martian Sand Dunes. J. Sediment. Res. 77, 607-614.

Jouannic, G., 2012. Morphological study of gullies formation on Martian dunes: Comparative study Earth/Mars. (PhD thesis) University Paris-Sud, Paris.

Jouannic, J., Gargani, J., Conway, S.J., Costard, F., Balme, M.R., Patel, M.R., Massé, M., Marmo, C., Jomelli, V., Ori, G.G., 2015. Laboratory simulation of debris flows over sand dunes: Insights into gully-formation (Mars). Geomorphology 231, 101-115. http://dx.doi.org/10.1016/j.geomorph.2014.12.007.

Jouannic, J., Gargani, J., Costard, F., Ori, G.G., Marmo, C., Schmidt, F., Lucas, A., 2012. Morphological and mechanical characterization of gullies in a periglacial environment: The case of the Russell crater dune Mars. Planet. Space. Sci. 71, 3854. http://dx.doi.org/10.1016/j.pss.2012.07.005.

Kereszturi, A., Möhlmann, D., Berczi, S., Ganti, T., Horvath, A., Sik, A., Szathmary, E., 2011. Possible role of brines in the darkening and flow-like features on the Martian polar based on HiRISE images. Planet. Space Sci. 59, 1413-1427. http://dx.doi.org/10.1016/j.pss.2011.05.012.

Kereszturi, A., Möhlmann, D., Berczi, S., Ganti, T., Kuti, A., Sik, A., Horvath, A., 2009. Recent rheologic processes on dark polar dunes of Mars: Driven by interfacial water? Icarus 201, 492-503. http://dx.doi.org/10.1016/j.icarus.2009.01.014.

Kieffer, H. H., 2000. Annual punctuated $\mathrm{CO}_{2}$ slab-ice and jets on Mars. $2^{\text {nd }}$ Int. Conf. Mars Polar Sci. Abstract 4095.

Kieffer, H.H., 2007. Cold jets in the Martina polar caps, J. Geophys. Res. 112. E08005. http://dx.doi.org/10.1029/2006JE002816. 
849

850

851

852

853

854

855

856

857

858

859

860

861

862

863

864

865

866

867

868

869

870

871

872

873

874

875

876

877

Kieffer, H.H., Christensen, P.R., Titus, T.N., 2006. $\mathrm{CO}_{2}$ jets formed by sublimation beneath translucent slab ice in Mars seasonal south polar ice cap. Nature 442, 793796. http://dx.doi.org/10.1038/nature04945.

Kleinhans, M. G., Markies, H., de Vet, S. J., in't Veld, A. C., Postema, F. N., 2011. Static and dynamic angles of repose in loose granular materials under reduced gravity, J. Geophys. Res. 116. E11004. http://dx.doi.org/10.1029/2011JE003865.

Knauth, J.P., Burt, D.M., 2002. Eutectic brines on Mars: Origin and possible relation to young seepage features. Icarus 158, 267-271. http://dx.doi.org/10.1006/icar.2002.6866.

Kneissl, T., Reiss, D., Van Gasselt, S., Neukum, G., 2010. Distribution and orientation of northern-hemisphere gullies on Mars from the evaluation of HRSC and MOC-NA data. Earth Planet. Sci. Lett. 294, 357-367. http://dx.doi.org/ 10.1016/j.epsl.2009.05.018.

Kreslavsky, M., Head, J., Marchant, D., 2008. Periods of active permafrost layer formation during the geological history of Mars: Implications for circum-polar and midlatitude surface processes. Planet. Space Sci 56, 289-302. http://dx.doi.org/ doi:10.1016/j.pss.2006.02.010

Laskar, J., Correia, A. C. M., Gastineau, M., Joutel, F., Levrard, B., Robutel, P., 2004. Long term evolution and chaotic diffusion of the insolation quantities of Mars. Icarus, 170, 343-364. http://dx.doi.org/10. 1016/j.icarus.2004.04.005.

Malin, M.C., Edgett, K.S., 2000. Evidence for recent groundwater seepage and surface runoff on Mars. Sciences 288, 2330-2335. http://dx.doi.org/10.1126/science.288.5475.233.

Mangold, N., Costard, F. Forget. F., 2003. Debris flows over sand dunes on Mars: Evidence for liquid water, J. Geophys. Res., 108 (E4), 5027. http://dx.doi.org/10.1029/2002JE001958.

Mangold, N., Mangeney, A., Migeon, V. Ansan, V., Lucas, A., Baratoux, D., Bouchut, F., 2010. Sinuous gullies on Mars: Frequency, distribution, and implications for flow properties. J. Geophys. Res. 115, E11001. http://dx.doi.org/10.1029/2009JE003540. 
878

879

880

881

882

883

884

885

886

887

888

889

890

891

892

893

894

895

896

897

898

899

900

901

902

903

904

905

Massé, M., Beck, P., Schmitt, B., Pommerol, A., McEwene, A., Chevrier, V., Brissaud, O., Séjourné, A., 2014. Spectroscopy and detectability of liquid brines on mars. Planet. Space Sci. 92, 136-149. http://dx.doi.org/10.1016/j.pss.2014.01.018i.

McEwen, A. S. et al., 2010. The High Resolution Imaging Science Experiment (HiRISE) during MRO's Primary Science Phase (PSP). Icarus 205, 2-37. http://dx.doi.org/doi:10.1016/j.icarus.2009.04.023.

McEwen, A., Dundas, C., Mattson, S., Toigo, A., Ojha, L., Wray, J., Chojnacki, M., Byrne, S., Murchie, S., Thomas, N., 2014. Recurring slope lineae in equatorial regions of Mars. Nature. Geosc. 7, 53-58. http://dx.doi.org/10.1038/NGEO2014.

McEwen, A., Eliason, E., 2007. Information for scientific users of HiRISE color products. www.hirise.Ipl.arizona.edu.

McEwen, A.S., Ojha, O., Dundas, C.M., Mattson, S.S., Byrne, S., Wray, J.J., Cull, S.C., Murchie, S.L., Thomas, N., Gulick, V.C., 2011. Seasonal flows on warm Martian slopes. Science 333, 740-743. http://dx.doi.org/10.1126/science.1204816.

Mellon, M. T., Jakosky, B.M., 1993. Geographic variations in the thermal and diffusive stability of ground ice on Mars, J. Geophys. Res. 98, 3345-3364. http://dx.doi.org/10.1029/92JE02355.

Mischna, M.A., Richardson, M.I., Wilson, R.J., McCleese, D.J., 2003. On the orbital forcing of martian water and cycles: A general circulation model study with simplified volatile schemes. J. Geophys. Res. Planet 108 (E6). http://dx.doi.org/10.1029/2003JE002051. 5062.

Miyamoto, H., Dohm, J.M., Baker, V.R., Beyer, R.A., Bourke, M., 2004. Dynamics of unusual debris flows on Martian sand dunes. J. Geophys. Res. Lett. 31, L13701. http://dx.doi.org/10.1029/2004GL020313.

Möhlmann, D., Kereszturi, A., 2010. Viscous liquid film flow on dune slopes of Mars. Icarus 207, 654-658. http://dx.doi.org/10.1016/2010.01.002.

Murchie, S.L., Arvidson, R.E., Bedini, P., Beisser, K., Bibring, J-P., et al., 2004. CRISM (Compact Reconnaissance Imaging Spectrometer for Mars) on MRO (Mars 
906 Reconnaissance Orbiter), Proc. SPIE 5660, Instruments, Science, and Methods for 907 Geospace and Planetary Remote Sensing, 66. http://dx.doi.org/10.1117/12.578976.

908 Ojha, L., Wilhelm, M.B., Murchie, S.L., McEwen,A.S., Wray, J.J., Hanley, J., Massé, 909 M., and Chojnacki, M. 2015. Spectral evidence for hydrated salts in seasonal flows on Mars. Nature Geosc. 8, 829-832. http://dx.doi.org/10.1038/ngeo2546.

Paige, D.A., Keegan, K.D., 1994. Thermal and albedo mapping of the polar regions 912 of Mars using Viking thermal mapper observations: 2. South polar region. J. Geophys. Res. 99 (E12), 25993-2601. http://dx.doi.org/10.1029/93JE03429.

Pilorget, C., Forget, F., 2015. Formation of gullies on Mars by debris flows triggered by $\mathrm{CO}_{2}$ sublimation. Nature Geosc. 9, 65-69. http://dx.doi.org/10.1038/NGEO2619.

Piqueux, S., Byrne, S., Richardson, M., 2003. Sublimation of Mars southern seasonal $\mathrm{CO}_{2}$ ice cap and the formation of spiders. J. Geophys. Res. 108 (E8) 5084. http://dx.doi.org/10.1029/2002JE002007.

Piqueux, S., Christensen, P.R., 2008. North and south subice gas flow and venting of the seasonal caps of Mars: A major geomorphological agent. J. Geophy. Res. Planets 113 (E6). http://dx.doi.org/10.1029/2007JE003009.

Raack, J., Reiss, D., Appéré, T., Vincendon, M., Ruesch, O., Hiesinger, H., 2015. Present-day seasonal gully activity in a south polar pit (Sisyphi Cavi) on Mars. Icarus 251, 226-243. http://dx.doi.org/10.1016/j.icarus.2014.03.040.

Reiss, D., Jaumann, R., 2003. Recent debris flows on Mars: Seasonal observations 926 of the Russell Crater dunefield. Geophys. Res. Lett. 30 (6):060000-1. 927 http://dx.doi.org/10.1029/2002GL016704.

928 Reiss, D., Jaumann, R., Kereszturi, A., Sik, A., Neukum, G., 2007. Gullies and 929 avalanches scars on martian dark dunes. Lunar Planet. Sci. 38. Abstract 1993.

930 Reiss, D., Erkeling, G., Bauch, K.E. and Hiesinger, H. 2010. Evidence for present day 931 Gully on the Russell crater dunefield, Mars. Geophys. Res. Lett. 37, L06203. 932 http://dx.doi.org/10.1029/20090421192. 
933 Schorghofer, N., Edgett, K.S., 2006. Seasonal surface frost at Low latitudes on Mars. Icarus 180, 321-334. http://dx.doi.org/10.1016/j.icarus.2005.08.022.

935

936

937

938

939

940

941

942

943

944

945

946

947

948

949

950

951

952

953

954

955

956

957

958

959

960

Smith, D. E., Zuber, M. T., Neumann,

G. A. 2001. Seasonal Variations of Snow Depth on Mars. Science, 2141-2146. http://dx.doi.org/10.1126/science.1066556.

Statella, T., Pina, P., Antônio da Silva, E., 2015. Extensive computation of albedo contrast between martian dust devil tracks and their neighboring regions. Icarus 250 , 43-52. http://dx.doi.org/10.1016/j.icarus.2014.11.023.

Stillman, D., Michaels, T., Grimm, R., Harrison, K. 2014. New observations of martian southern mid-latitude recurring slope lineae (RSL) imply formation by freshwater subsurface flows. Icarus 233, 328-341. http://dx.doi.org/10.1016/j.icarus.2014.01.017.

Sullivan, R., Anderson, R., Biesiadecki, J., Bond, T., Stewart, H., 2011. Cohesions, friction angles, and other physical properties of Martian regolith from Mars Exploration Rover wheel trenches and wheel scuffs. J. Geophys. Res. 116, E02006. http://dx.doi.org/10.1029/2010JE003625.

Sylvest, M.E., Conway, S.J., Patel, M.R., Dixon, J., Barnes, A., 2016. Laboratory observations of mass wasting triggered by sublimation of condensed $\mathrm{CO}_{2}$ frost under Martian conditions. Lunar Planet. Sci. 46. Abstract 2667.

Thomas, P., 1982. Present wind activity on Mars - Relation to large latitudinal zoned sediment deposits. J. Geophys. Res. 87, 9999-10008. http://dx.doi.org/10.1029/JB087iB12p09999.

Védie, E., Costard, F., Font, M., Lagarde, J.L., 2008. Laboratory simulations of Martian gullies on sand dunes. Geophys. Res. Lett. 35, L21501. http://dx.doi.org/10.1029/2008GL035638, 2008.

Verba, C.A., Greissler, P.E., Titus, T.N., Waller, D.A., 2010. Observations from High Resolution Imaging Science Experiment (HiRISE); Martian dust devils in Gusev and Russell craters. J. Geophys. Res. 115, E09002. 
961 Vincendon, M., Mustard, J., Forget, F., Kreslavsky, M., Spiga, A., Murchie, S., 962 Bibring, J-P., 2010a. Near-tropical subsurface ice on Mars. Geophys. Res. Lett. 37, 963 L01202. http://dx.doi.org/10.1029/2009GL041426, 2010.

964 Vincendon, M., Forget, F., Mustard, J., 2010b. Water ice at low to midlatitudes on 965 Mars. J. Geophys. Res. 115, E10001. http://dx.doi.org/10.1029/2010JE003584, 9662010.

967 Vincendon, M. 2015. Identification of Mars gully activity types associated with ice 968 composition. J. Geophys. Res. 120. 969 http://dx.doi.org/doi:10.1002/2015JE004909.

970 Williams, K.E., Toon, O.B., Heldmann, J.L., Mellon, M.T., 2009. Ancient melting of 971 mid-latitude snowpacks on Mars as a water source for gullies. Icarus 200, 418-425. 972 http://dx.doi.org/10.1016/j.icarus.2008.12.013. 